\title{
Deprescribing Interventions among Community-Dwelling Older Adults: A Systematic Review of Economic Evaluations
}

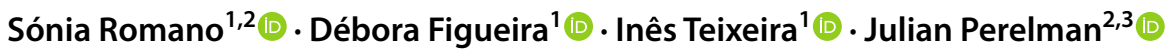

Accepted: 28 November 2021

(c) The Author(s), under exclusive licence to Springer Nature Switzerland AG 2021

\begin{abstract}
Background Deprescribing can reduce the use of inappropriate or unnecessary medication; however, the economic value of such interventions is uncertain.

Objective This study seeks to identify and synthetise the economic evidence of deprescribing interventions among community-dwelling older adults.

Methods Full economic evaluation studies of deprescribing interventions, conducted in the community or primary care settings, in community-dwelling adults aged $\geq 65$ years were systematically reviewed. MEDLINE, EconLit, Scopus, Web of Science, CEA-TUFTS, CRD York and Google Scholar databases were searched from inception to February 2021. Two researchers independently screened all retrieved articles according to inclusion and exclusion criteria. The main outcome was the economic impact of the intervention from any perspective, converted into 2019 US Dollars. The World Health Organization threshold of 1 gross domestic product per capita was used to define cost effectiveness. Studies were appraised for methodological quality using the extended Consensus on Health Economics Criteria checklist.

Results Of 6154 articles identified by the search strategy, 14 papers assessing 13 different interventions were included. Most deprescribing interventions included some type of medication review with or without a supportive educational component $(n=11,85 \%)$, and in general were delivered within a pharmacist-physician care collaboration. Settings included community pharmacies, primary care/outpatient clinics and patients' homes. All economic evaluations were conducted within a time horizon varying from 2 to 12 months with outcomes in most of the studies derived from a single clinical trial. Main health outcomes were reported in terms of quality-adjusted life-years, prevented number of falls and the medication appropriateness index. Cost effectiveness ranged from dominant to an incremental cost-effectiveness ratio of $\$ 112,932$ per quality-adjusted life-year, a value above the country's World Health Organization threshold. Overall, $85 \%$ of the interventions were cost saving, dominated usual care or were cost effective considering 1 gross domestic product per capita. Nine studies scored $>80 \%$ (good) and two scored $\leq 50 \%$ (low) on critical quality appraisal.

Conclusions There is a growing interest in economic evaluations of deprescribing interventions focused on communitydwelling older adults. Although results varied across setting, time horizon and intervention, most were cost effective according to the World Health Organization threshold. Deprescribing interventions are promising from an economic viewpoint, but more studies are needed.
\end{abstract}

Sónia Romano

sonia.romano@anf.pt

1 Centre for Health Evaluation and Research/Infosaúde, National Association of Pharmacies (CEFAR-IF/ANF), Rua Marechal Saldanha 1, 1249-069 Lisbon, Portugal

2 Escola Nacional de Saúde Pública, Universidade Nova de Lisboa, Lisbon, Portugal

3 Centro de Investigação em Saúde Pública, Lisbon, Portugal

\section{Key Points for Decision Makers}

Older adults are often exposed to inappropriate or unnecessary medication that can cause harm to patients and high costs to the health system.

Economic evidence of deprescribing interventions for community-dwelling adults is recent.

The results of this review suggest that deprescribing interventions for community-dwelling older adults are promising from an economic viewpoint. 


\section{Introduction}

Population ageing is one of the greatest social and economic challenges worldwide. Over the last two decades, the number of older people in the EU-27 has risen almost six times faster than the overall population [1]. Despite an increment in life expectancy, there is no guarantee of healthy ageing [2-4]. The prevalence of multimorbidity (presence of two or more chronic diseases in the same individual) among older adults is very high and continues to grow, exposing them to multiple medicines, commonly referred to as polypharmacy [5-7]. Polypharmacy is related to an increased risk of adverse drug events, use of potentially inappropriate medication (PIM), and greater health services utilisation, morbidity and mortality $[8,9]$. About $30 \%$ of community-dwelling older European adults take at least one PIM [10], i.e., a medicine posing a risk of harm that outweighs the clinical benefit $[10,11]$. Deprescribing, in a simple definition, is an intervention supervised by a health professional of reducing or withdrawing a medication that might be causing harm or might no longer be of benefit $[12,13]$. Several strategies to deprescribe have been developed, including drug-specific guidelines, educational interventions, medication reviews and audits of prescription practices [14, 15].

This subject is gaining attention and various systematic reviews of deprescribing interventions and their effectiveness for older people have been published. Overall, deprescribing seems to be safe, with evidence suggesting that these interventions may result in small reductions in falls $[16,17]$, mortality [17-20], use of PIMs [17, 21] and hospital admissions [17-19] — all with little to no effect on healthrelated quality of life (HRQoL) [17-19, 22]. A recent overview of systematic reviews of interventions to reduce the prescription of PIMs suggested potential benefits, even if modest, of different interventions depending on the study design, intervention type and population characteristics [23]. Considering the ageing population, polypharmacy and associated healthcare costs, it is important to determine if these minor benefits are worth it from an economic viewpoint.

As deprescribing interventions are potentially complex and require highly skilled staff and time to be undertaken, high implementation costs can be expected. In a context of limited resources, economic evaluations (EEs) play an increasingly important role in decision making, informing the issue of whether interventions represent a cost-effective strategy. To the best of our knowledge, no systematic review has addressed the economic value of deprescribing interventions for community-dwelling older adults. Moreover, a review focused on this vulnerable population is valuable as their needs, preferences and behaviours may impact the deprescribing process and outcomes [24, 25]. This systematic review seeks to identify and synthesise available evidence of the economic value of deprescribing interventions among community-dwelling older adults in community or primary care settings.

\section{Methods}

This review followed current guidance for conducting and reporting systematic reviews, including guidance for undertaking reviews on healthcare interventions by the Centre for Reviews and Dissemination of the University of York [26] and recommendations from the PRISMA (Preferred Reporting Items for Systematic Reviews and Meta-Analyses) 2020 statement, an updated guideline for reporting systematic reviews [27].

\subsection{Eligibility Criteria}

The population, intervention, comparator, outcome and study-design (PICOS) approach [26] was used to guide the search strategy and synthesis of evidence gathered from single studies:

- Population: community-dwelling (non-institutionalised) older adults (aged $\geq 65$ years, the cut-off commonly defined in developed world economies [28]).

- Intervention: any intervention conducted in the community or primary care settings that includes deprescribing inappropriate medicines, i.e. identifying and reducing medicine dosage or discontinuing unnecessary medications in which existing or potential harms outweigh the potential benefits $[12,13]$. Intervention procedures can include any educational approaches focused on patients and/or in doctors, medication reviews or any other framework that explores deprescribing medicines. Study investigators defined community setting as community pharmacies, primary care/general practices, outpatient care (clinics or hospitals) and patients' homes.

- Comparator: usual care as described by the study.

- Outcomes: the main outcome is the economic impact of the intervention regardless of how it is expressed (incremental cost-effectiveness ratios [ICERs], dominance, etc.), and regardless of the perspective.

- Study-design: full EEs as defined by Drummond et al., i.e. studies comparing both benefits and costs of alternative courses of action [29].

Studies were excluded if: (i) the effectiveness of the intervention among the older adults could not be isolated; (ii) the intervention was not focused on reducing the dose or withdrawing medicines (e.g. adherence medication reviews); (iii) the intervention was delivered in settings other than primary 
care or community settings (e.g. hospital inpatient or acute care; assisted living, nursing homes or geriatric wards); (iv) the studies did not include a full EE (e.g. studies measuring costs only); (v) studies did not report the mean costs, benefits or resource data that enabled the authors to estimate the ICER; and (vi) studies were presented as letters to editor/ editorials, health technology assessment reports not submitted to peer review, study protocols, academic theses, review articles and conference abstracts.

\subsection{Literature Search and Study Selection}

The following electronic databases were searched for journal articles and abstracts, from inception to February 2021: MEDLINE (PubMed), EconLit, Scopus, Web of Science, CEA-TUFTS registry and CRD York database (DARE, National Health Service EE Database; ceased to be updated in March 2015). Google Scholar was also searched. In addition, relevant grey literature was explored using the Google search engine and the International HTA Database. Complementary searches were made to identify possible additional articles through citation searches, reference checking and hand searching.

The search strategy was developed by one of the authors (SR) in consultation with the other authors (DF, IT, JP) using an iterative process, and comprised a variety of combinations of free-text synonymous and Medical Subject Heading (MeSH) terms. Although the main search terms were the same, the conventions of each database were adjusted accordingly. There were no date or language restrictions on the searches. The final search strings are presented in the Appendix 1 of the Electronic Supplementary Material (ESM). References identified as potentially eligible for inclusion were exported to an Excel® file. Duplicate articles were removed. Titles and abstracts were screened independently by two authors against the inclusion and exclusion criteria and labelled as include, exclude or uncertain (first screening). Two authors independently evaluated the full text of all articles classified as include and uncertain (second screening). In each step, discrepancies between reviewers were solved by discussion with a third author. The PRISMA flowchart as suggested by the PRISMA statement was used for the study selection report [27].

\subsection{Data Extraction}

Data from included papers were extracted by three authors (SR, DF, IT) and validated by a fourth investigator (JP), using a standardised data extraction template designed for this review. This template, based on the CRD recommendations for systematic reviews of EEs [26], was designed to systematically retrieve information from each included study on the following items: (1) general characteristics: first author, year of publication, country, title and funding sources; (2) effectiveness data: study design, population, intervention and comparator descriptions, setting, sample size, follow-up time, unit of effectiveness, effectiveness results and sources; (3) economic data: economic model/ design, perspective, time horizon, costs items (or categories) and sources, currency/year of costing, outcomes measures for ICER, ICER, discount rate, deterministic, and probabilistic sensitivity analysis and scenario analysis (methods and main findings). When not provided in the studies, the incremental analysis was performed by the authors.

Selected studies were classified according to the type of intervention provided, namely, educational or medication reviews with or without a supportive educational (patients and/or practitioners) component. In order to allow comparisons of results across countries and years, the investigators converted costs, incremental costs, ICERs, and reported thresholds on a sensitivity analysis to a common currency and year (\$US, 2019), through a web-based tool developed by the Campbell and Cochrane Economics Methods Group in collaboration with the Evidence for Policy and Practice Information and Co-ordinating Centre [30]. This tool uses the gross domestic product (GDP) deflator index to adjust the costs to a target price year and the purchasing power parities (PPP) to convert currencies. Purchasing power parities values of the International Monetary Fund were used. The international World Health Organization threshold for cost effectiveness was used as a reference [31]. For the purpose of this review, a strategy was considered cost effective only when the cost per disability-adjusted life-year (DALY) averted or quality-adjusted life-year (QALY) gained was less than 1 GDP per capita [31]. The threshold for each study was calculated considering The World Bank GDP per capita, PPP (\$US, 2019), of the country for which it was performed [32].

\subsection{Quality Assessment}

Three authors (SR, DF, IT) independently appraised the methodological quality of the included studies, using the extended Consensus on Health Economics Criteria list (CHEC-extended) [33, 34]. In case of doubts or disagreement, a consensus was obtained by discussion with a fourth author (JP). The CHEC-extended includes an additional question regarding model-based EEs compared to the original CHEC checklist [33-35], and is recommended for the assessment of both trial-based and model-based EEs [36]. This checklist was chosen because it allows parameters and analysis appropriateness assessment and is considered to 
entail a more detailed scrutiny than other common checklists [36, 37]. Twenty items were scored using: yes (1), no (0), unclear (0.5) or not applicable. The maximum score was 19 for trial-based EEs and 20 for model-based evaluations. The total score of each study was converted to a percentage, with values from zero to 100 . Final scores were categorised into three grades: low, moderate or good quality, using cut-off values of $\leq 50,51-75$ and $>75$, respectively. Higher scores denote higher quality.

\section{Results}

Figure 1 shows the PRISMA flowchart for the study selection. A total of 6149 records were identified through seven databases. After removing duplicates, 5382 records were eligible for review. In the first screening, 5298 records were excluded by applying the exclusion criteria, leaving 84 papers for full-text retrieval. An additional five papers were identified through citation search, obtaining 89 papers for the second screening. Of those, 74 were excluded and one was not retrieved. The remainder of 14 full EE papers [38-51] were included in the final review (Fig. 1). The main causes for the second screening exclusion were a population not exclusively aged 65 years or over, the type of intervention not focusing on deprescribing and the absence of a full EE analysis.

\subsection{Characteristics of Studies}

All of the included studies, with the exception of one from Taiwan [38], were conducted for Organization for Economic Co-operation and Development countries-three in the UK [39-41] and in the Netherlands [42-44], two in Spain [45, 46] and Canada [47, 48], and one in Ireland [49], Chile [50] and the USA [51]. Both EE studies conducted in Spain assessed the same service, the conSIGUE trial. Thus, 13 interventions assessed in 14 papers were reviewed. Of those, 11 interventions ascertained in $12 \mathrm{EE}$ studies were some type of medication review of services covering heterogenous older people, with polypharmacy $(n=7)[38,40,41,44-46$, $50,51]$, a history of falls and taking fall-risk-increasingdrugs [FRIDs] $(n=2)[42,43]$, taking medications on a regular basis of specific class(es) of PIMs [49], and very old persons taking two or more medicines who were discharged to their homes after an emergency department visit $(n=1)$

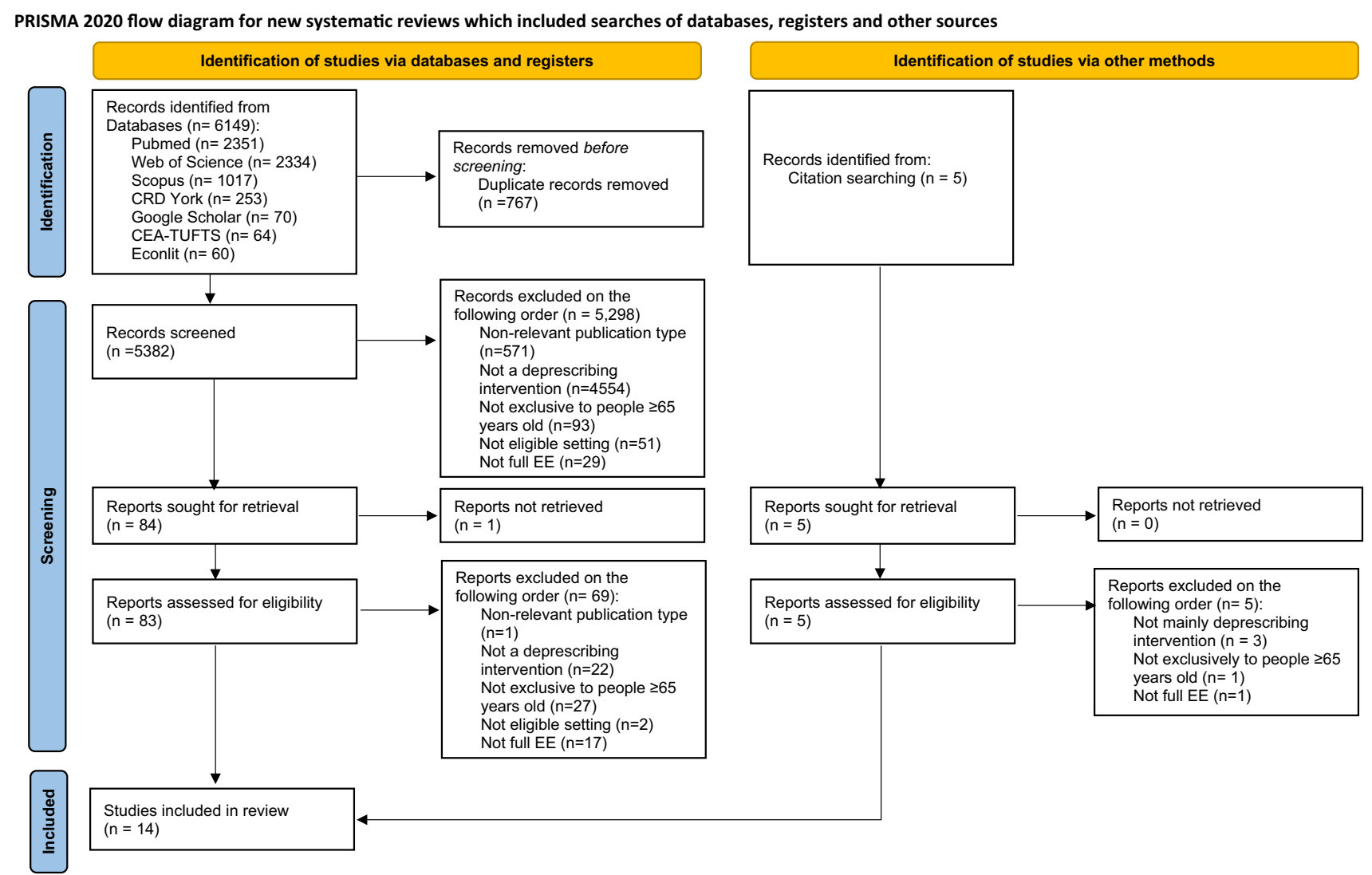

Fig. 1 PRISMA (Preferred Reporting Items for Systematic Reviews and Meta-Analyses) 2020 flowchart of study selection. EE economic evaluation 
[39]. The remaining two interventions were educational-only services delivered by pharmacists targeting patients taking a specific class of PIMs [47, 48].

The interventions were conducted at the community pharmacy $(n=6)$ [40, 41, 44-48], primary care centres/ general practices/geriatric/outpatient clinics $(n=6)[38,42$, $43,49-51$ ] or at the patient's home $(n=1)$ [39]. Across settings, most interventions were delivered by a community or clinical pharmacist working in collaboration with a physician, mostly general practitioners [38-41] [44-51]. Exceptions were the van der Velde et al. [42] and Polinder et al. studies [43], whose interventions were conducted at a geriatrics outpatient clinic and at multicentre outpatient clinics, respectively. Both interventions were led by geriatricians who consulted the prescribing physician if medication withdrawal was intended. The details of the included studies are summarised in Table 1.

\subsection{Methods and Inputs}

Most ( $n=10)$ EE studies were published recently, between 2015 and 2021 [38, 40, 43-50]. The oldest study was published in 1998 [51]. Eleven studies [38-41, 43, 44, 46-50] reported health outcomes in terms of QALYs, three of these also reported additional effectiveness measures-life-years gained, reduction in health-related complaints and mean number of PIPs [39, 44, 49]. One study reported as an additional outcome the total avoided medical expenditure [38], two expressed results in terms of clinical effectiveness measures only [42, 51] and one in terms of monetary benefit [45]. There were two studies with a societal perspective [43, 44], one with a hospital perspective [38] and 11 with a thirdparty payer perspective (public or private). Three studies did not state the perspective explicitly [38, 40, 43]. Most studies were undertaken alongside the effectiveness trial. One EE used data from a two-arm (fallers with and without a medication change) non-randomised observational study supported by a literature review and expert estimates [42]; another used a before-and-after comparison analysis, with intervention patients used as historical controls [40]; and a third one used a randomised, multiple interrupted time series [41]. Except for the two studies conducted in Canada $[47,48]$, which in addition to the randomised controlled trial (RCT) data, derived utility and cost values from the literature, the remaining studies used single RCTs (or cluster RCTs) as the basis for undertaking the EE [38, 39, 43-46, 49-51]. The two Canadian studies [47, 48] used a decision analytical model, combining a decision tree that represents treatment pathways (based on the 6-month RCT D-PRESCRIBE trial) with a Markov model (representing state transitions for older adults following the trial) in a 1-year time horizon for all analyses.
Regarding funding sources, four of the 14 studies had no sources of funding to declare [40, 47, 48, 50], one did not include any statement [51], five were supported by a combination of two entities-pharmaceutical industry and academia [42], pharmaceutical industry and Pharmaceutical Society $[45,46]$, association of pharmacies and Pharmaceutical Society [44], and Medical Research Council and primary care trusts [41]. Three studies received funding from research organisation grants $[39,43,49]$ and one from the Department of Health [38].

All studies except two considered some type of intervention costs and included medication expenses [38, 40]. Hospital admissions were also considered in all studies, as well as emergency department visits with the exception of the RESPECT trial [41]. Laboratory or diagnostic tests were reported in four studies [41, 48, 50, 51], and the two studies with the societal perspective $[43,44]$ considered institutional care (e.g. rehabilitation centres, nursing homes).

Regarding the type of interventions, two studies did not include potentially relevant costs, namely the cost of general practitioner visits [45, 46]. Most studies used countries' official data for cost valuation. Time horizons of the EEs were no longer than 12 months, and therefore discounting was not applicable. As for ICERs, one had to be recalculated because the original estimation considered only the drugs and intervention costs, failing to include other retrieved relevant medical costs (e.g. emergency room visits) [51], and another had to be estimated because it was not reported in the original paper [43]. Table 2 summarises the study findings.

\subsection{Quality Assessment}

Nine studies had a "good" [39, 41, 44-50] quality score, three were "moderate" $[40,42,43]$ and two a "low" [38, 51] quality assessment (Table 2). Overall, costs were measured appropriately in all studies. Moreover, their valuation was adequate in all studies except one [38]. The economic study design was considered appropriate in 12 studies, excluding two $[38,42]$ that did not include an appropriate comparison of mean benefits and costs. An appropriate incremental analysis of costs and outcomes of alternatives was also performed in 11 of 14 studies. The quality items assessed with lower scores were: (i) the time horizon, which varied between 2 and 12 months, was not sufficiently long to incorporate all potentially important differences in costs and consequences [53] (lifetime horizon is the most appropriate approach to the interventions under comparison, as events can occur over patients' lifetimes, according to most international guidelines [53-55]); (ii) the ethical and distributional issues, which were addressed satisfactorily in only one study [50], such as prioritising high-risk groups, or considering an equitable distribution of benefits across socioeconomic or other groups [29]; and (iii) the generalisability of the results 


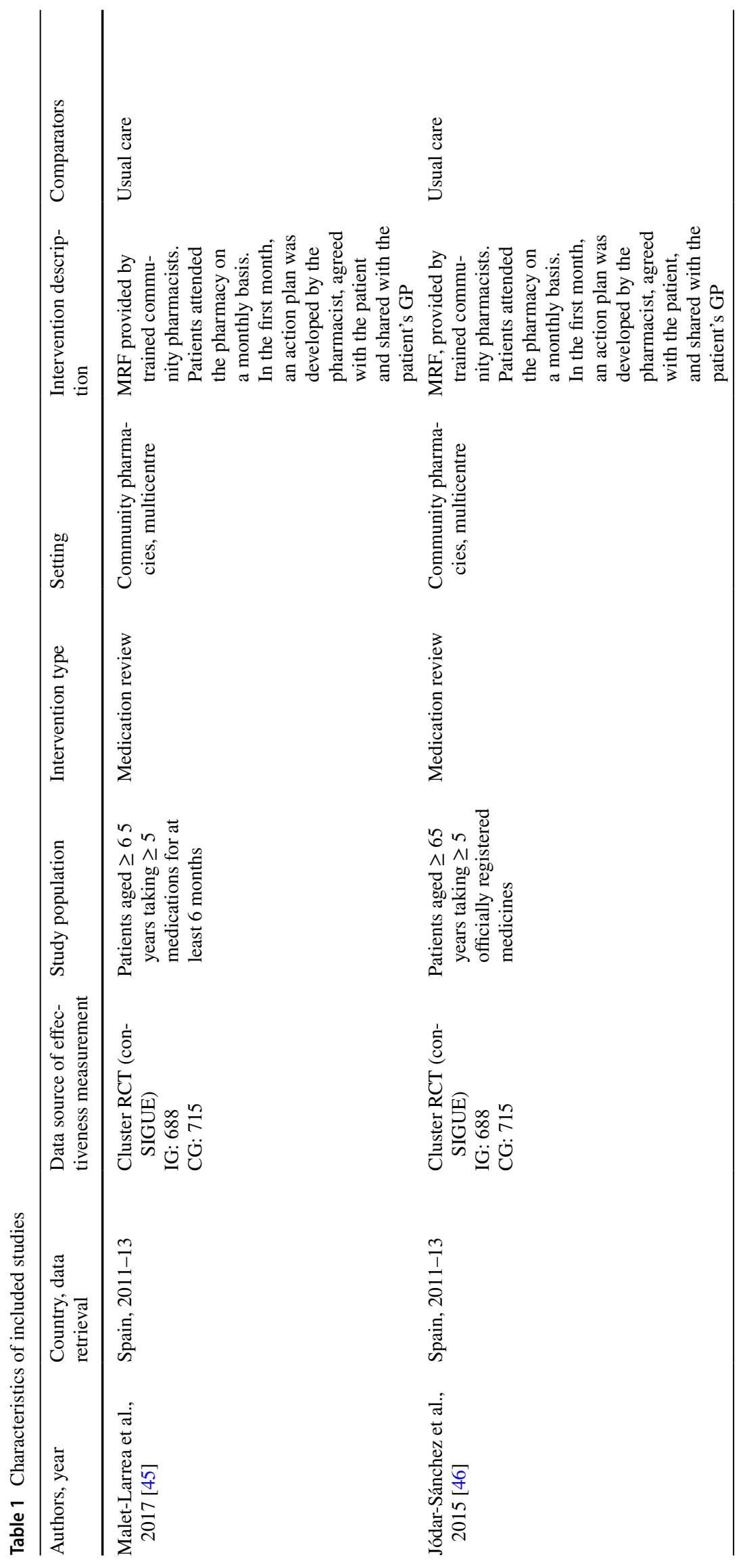

么 Adis 


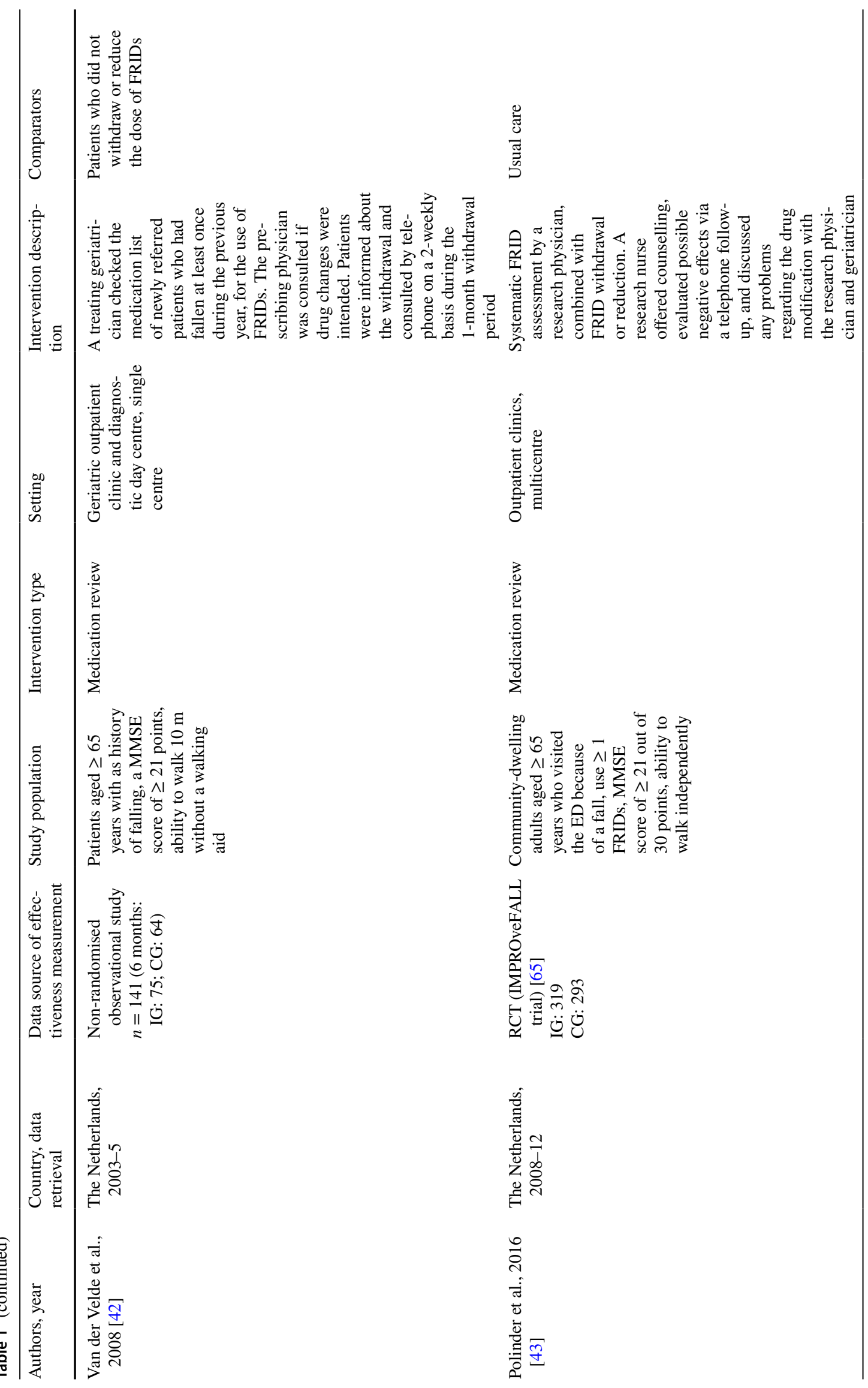




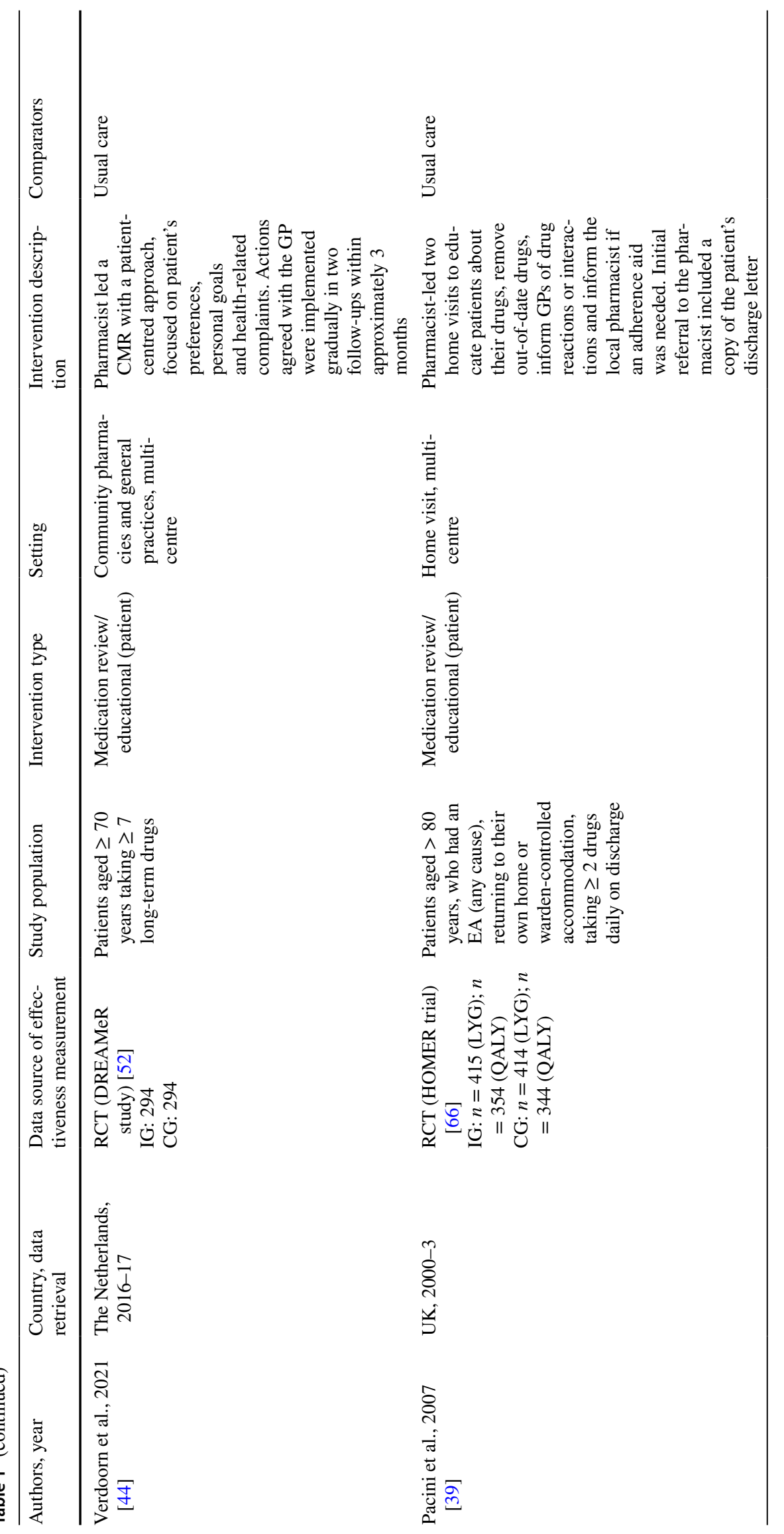




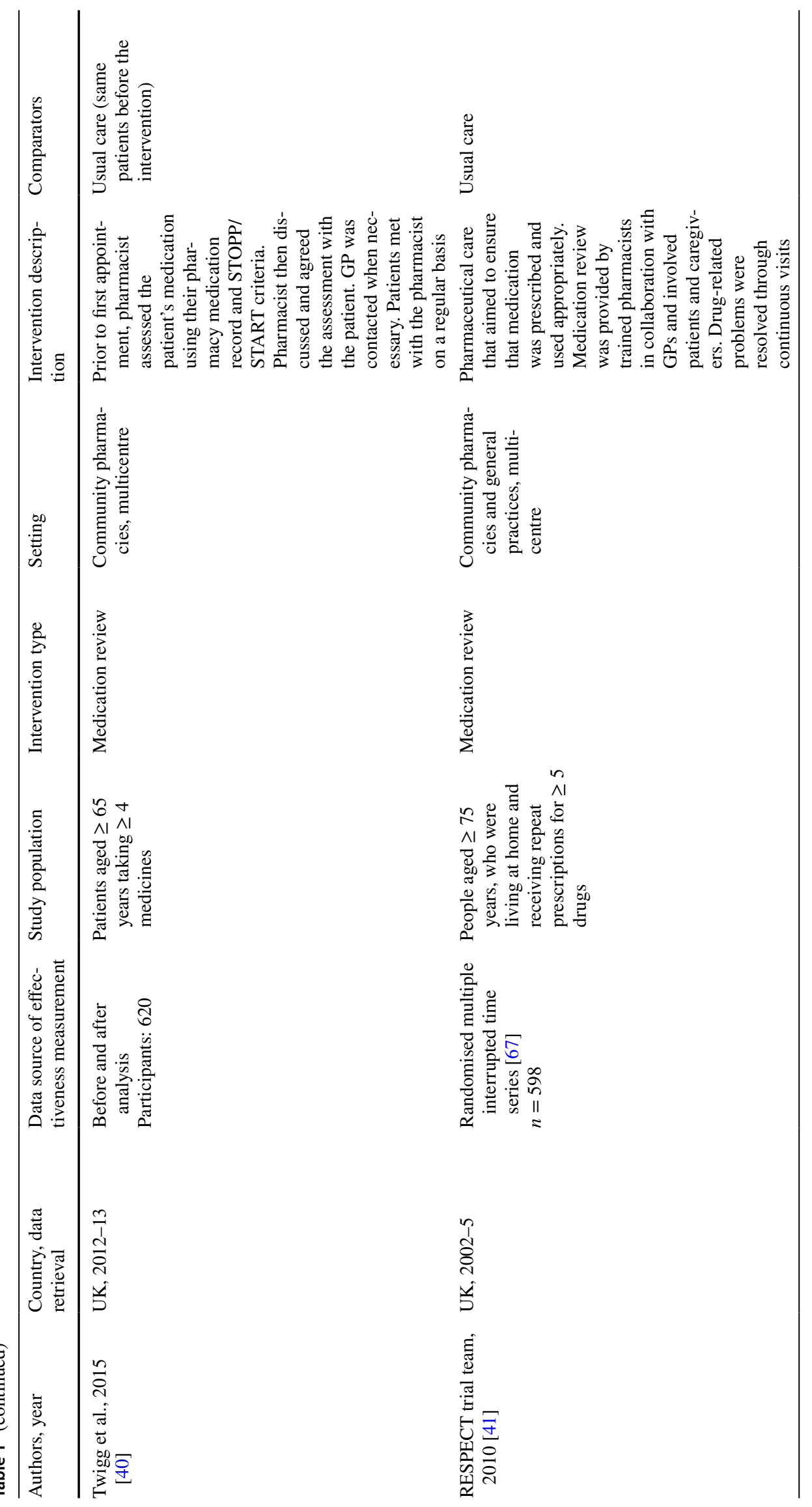




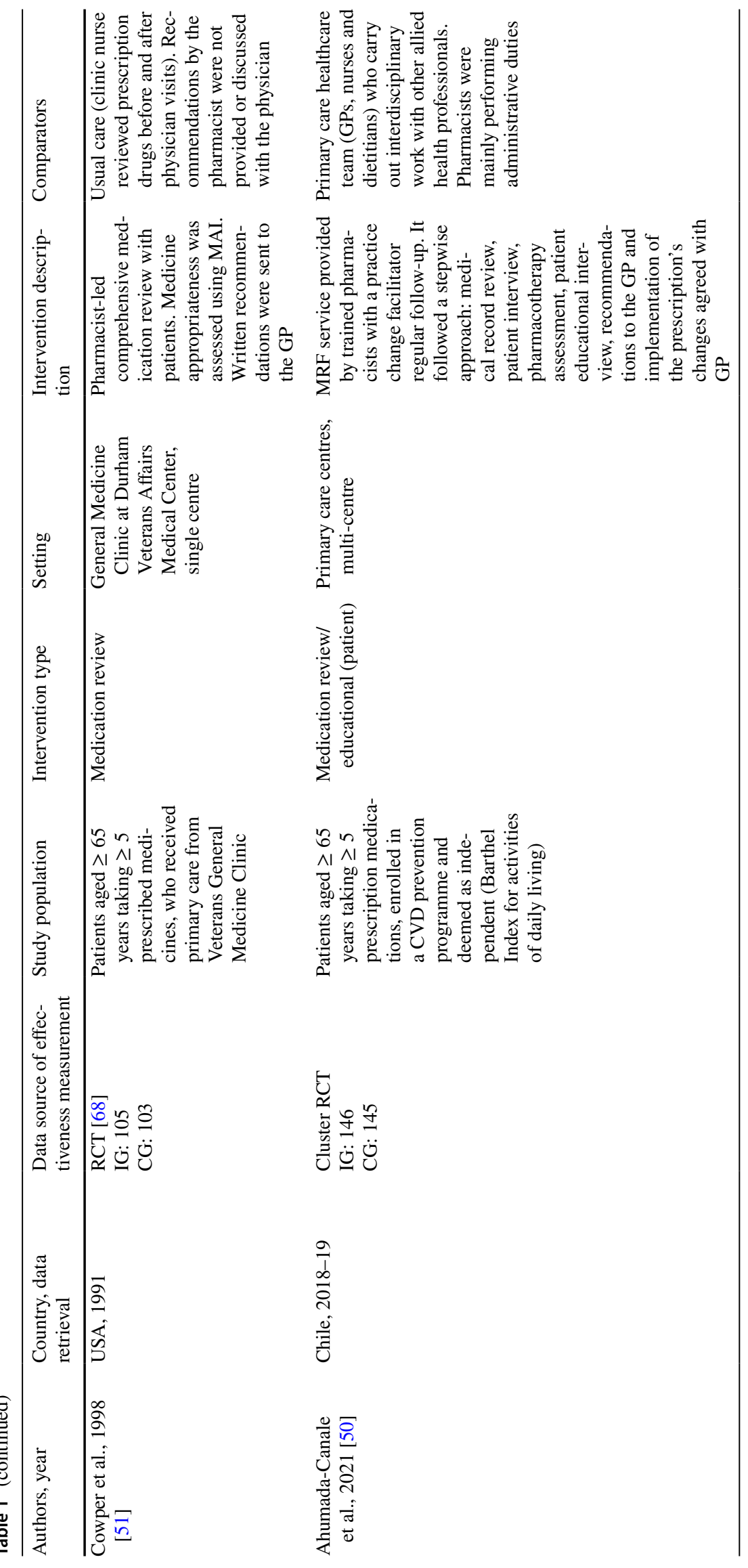

么 Adis 


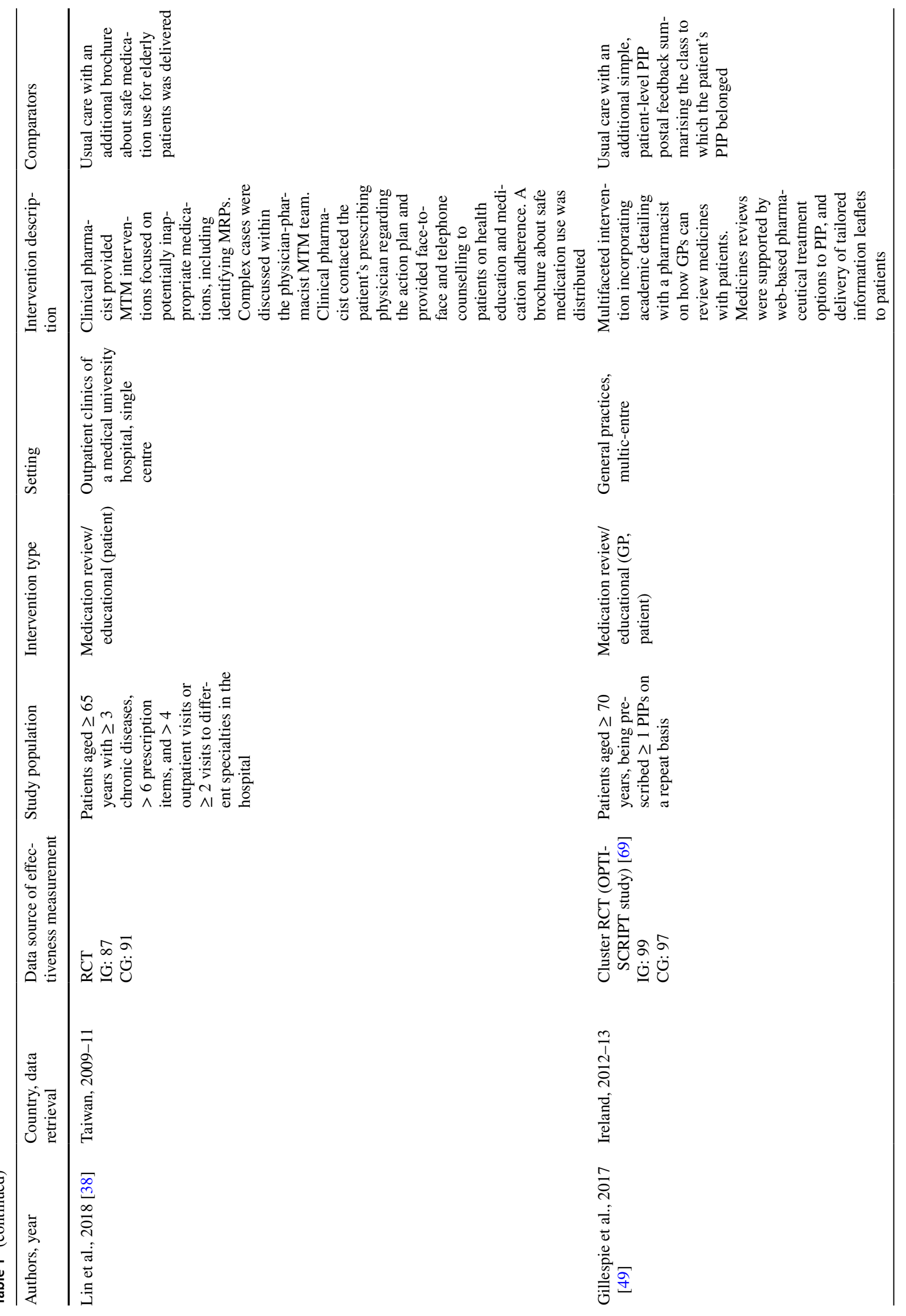




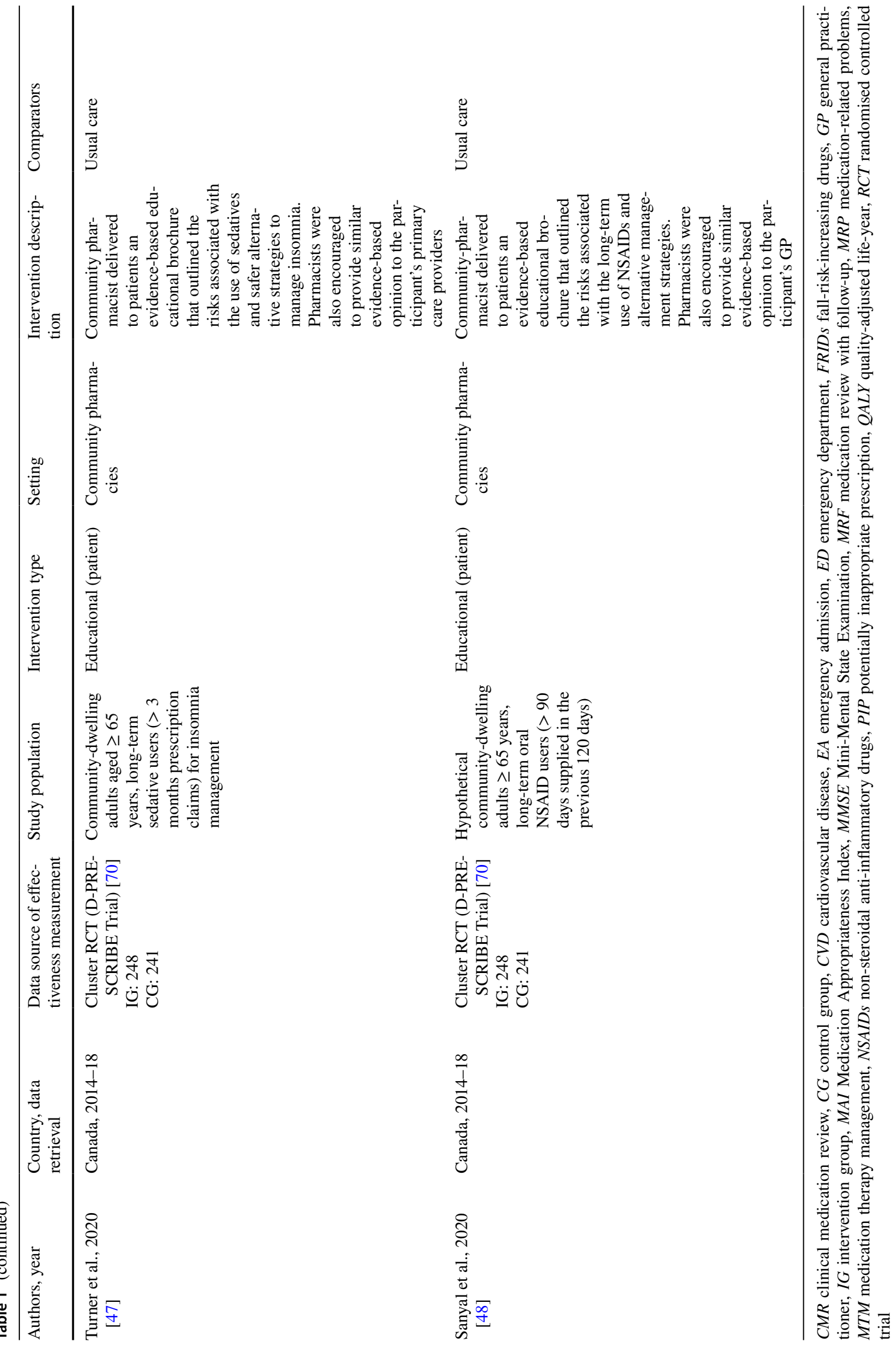




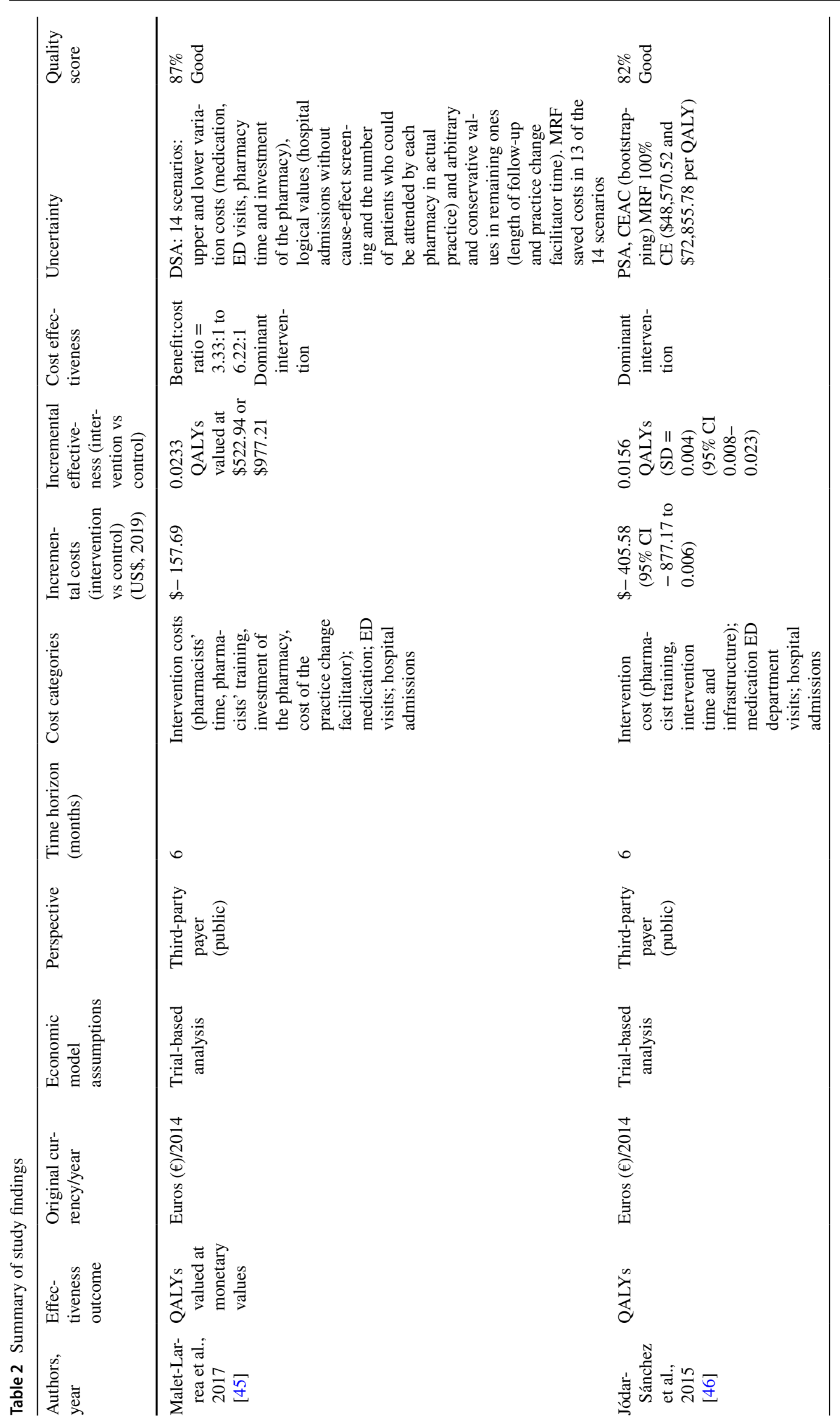




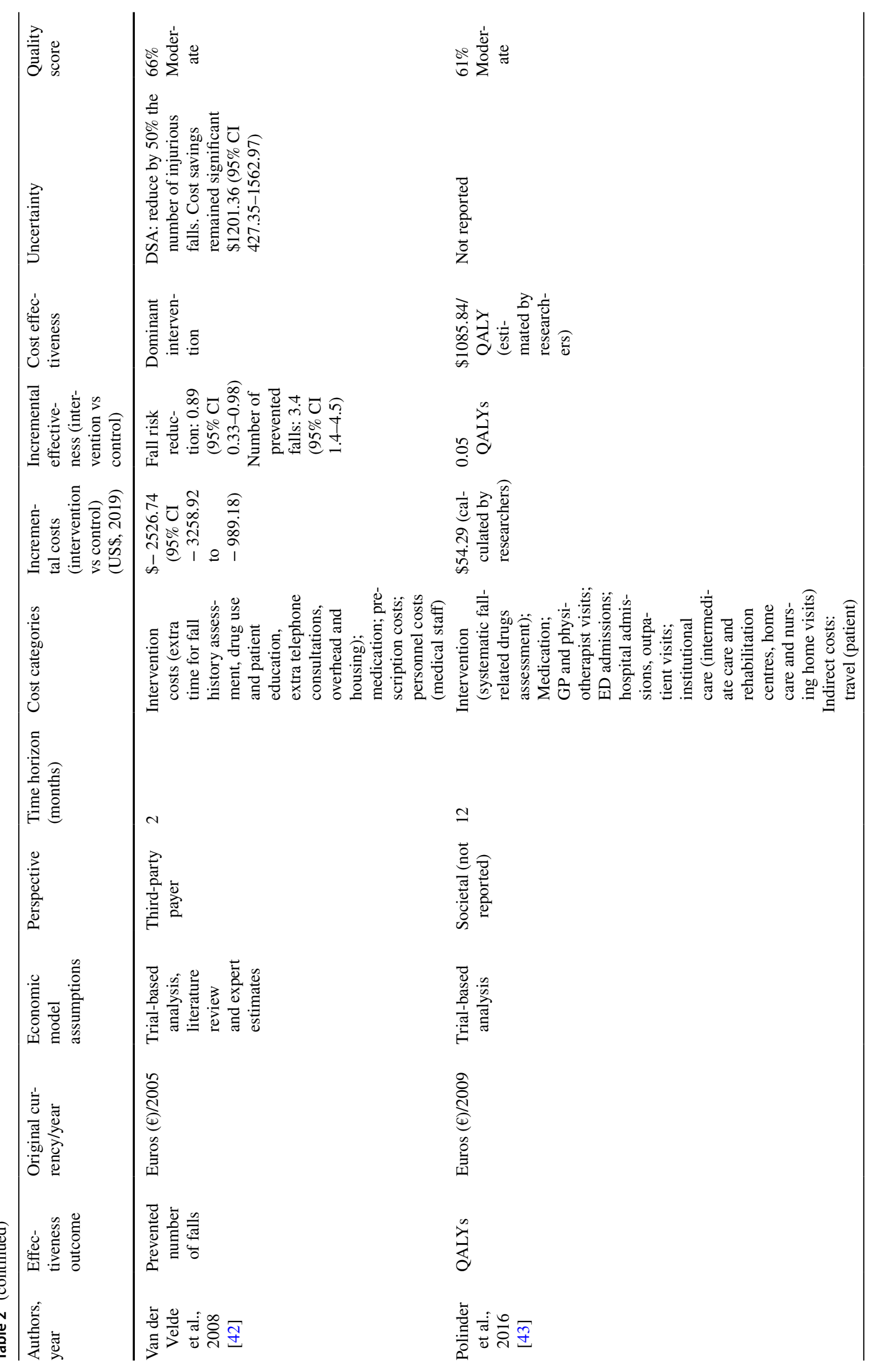




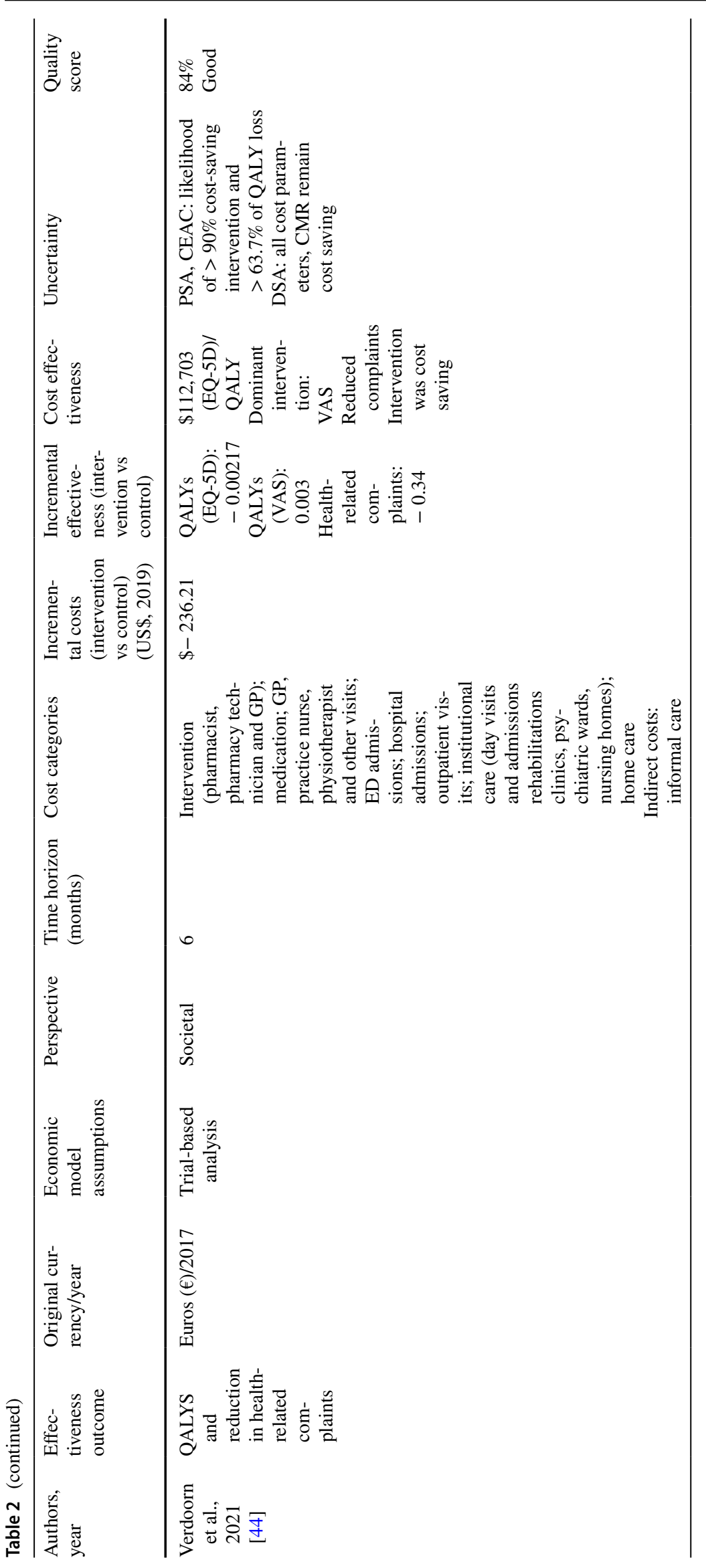




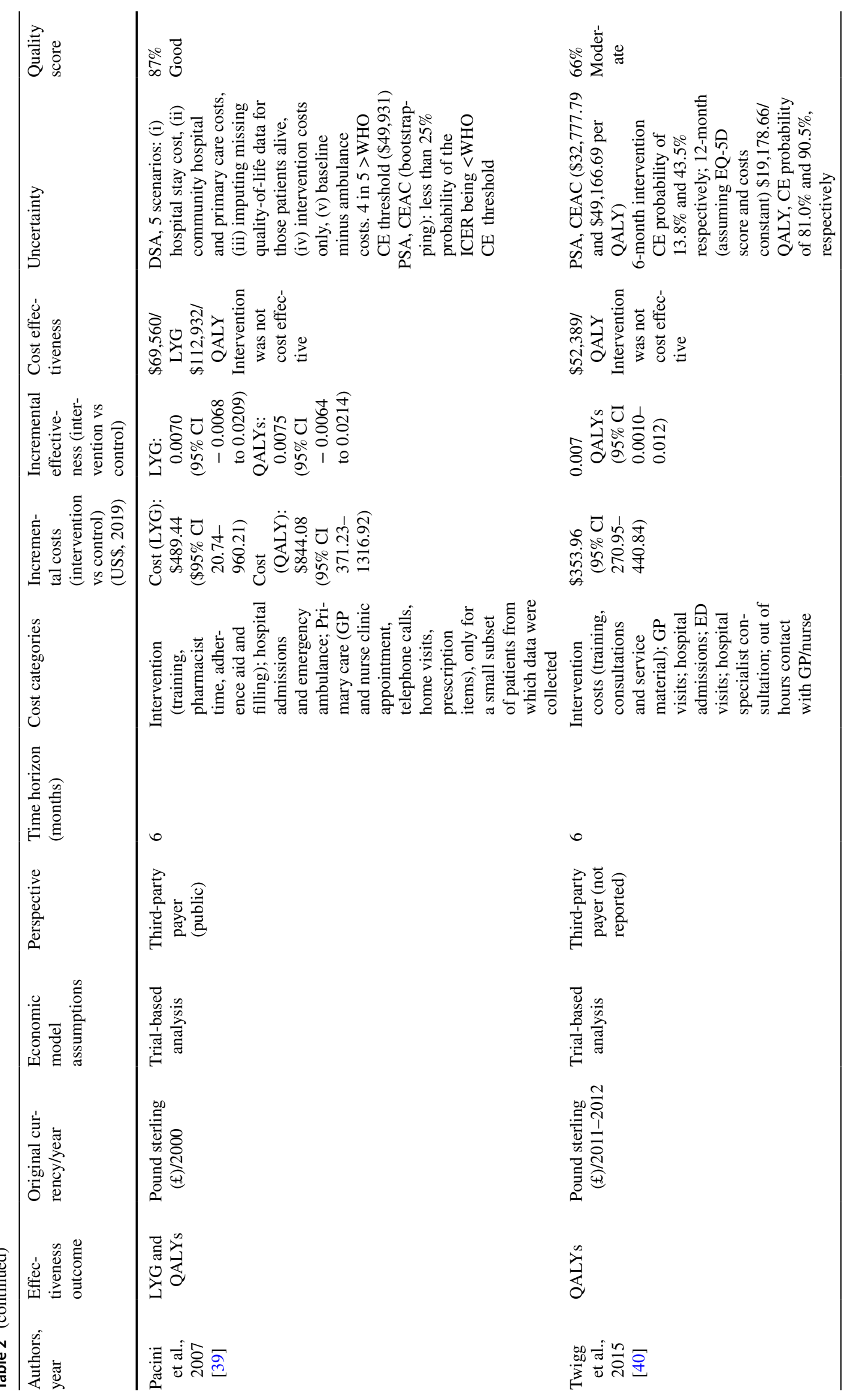




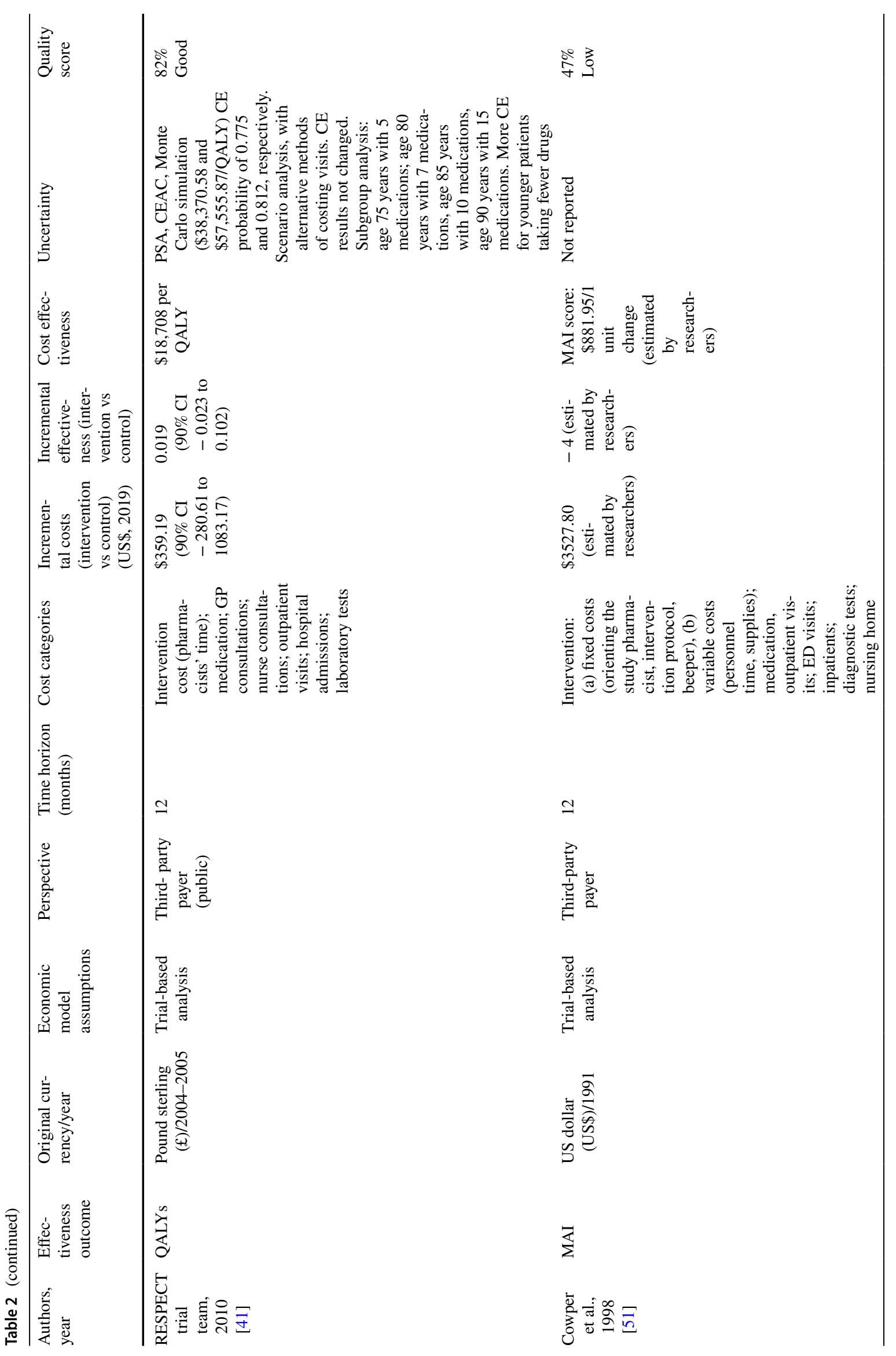


S. Romano et al.

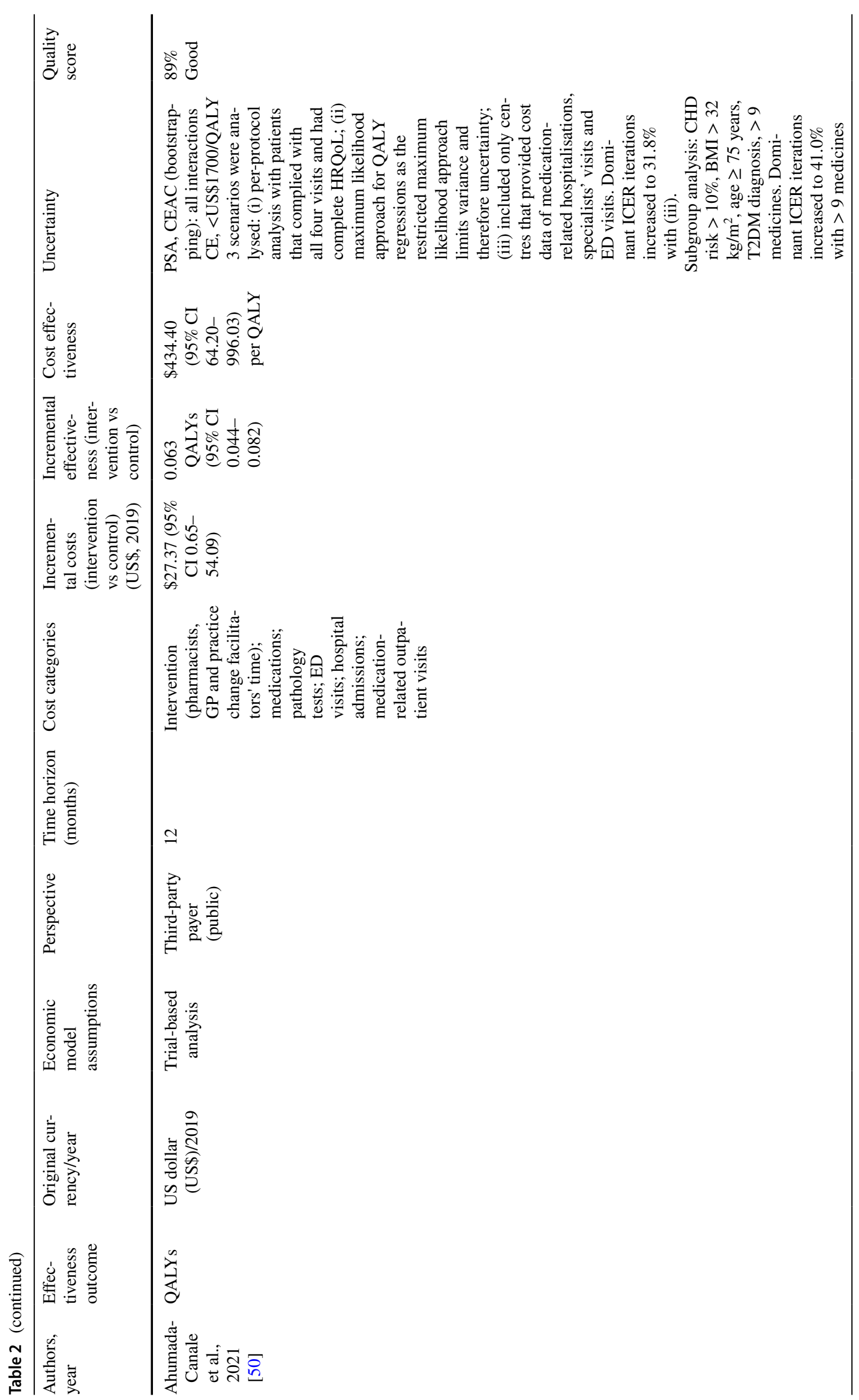

么 Odis 


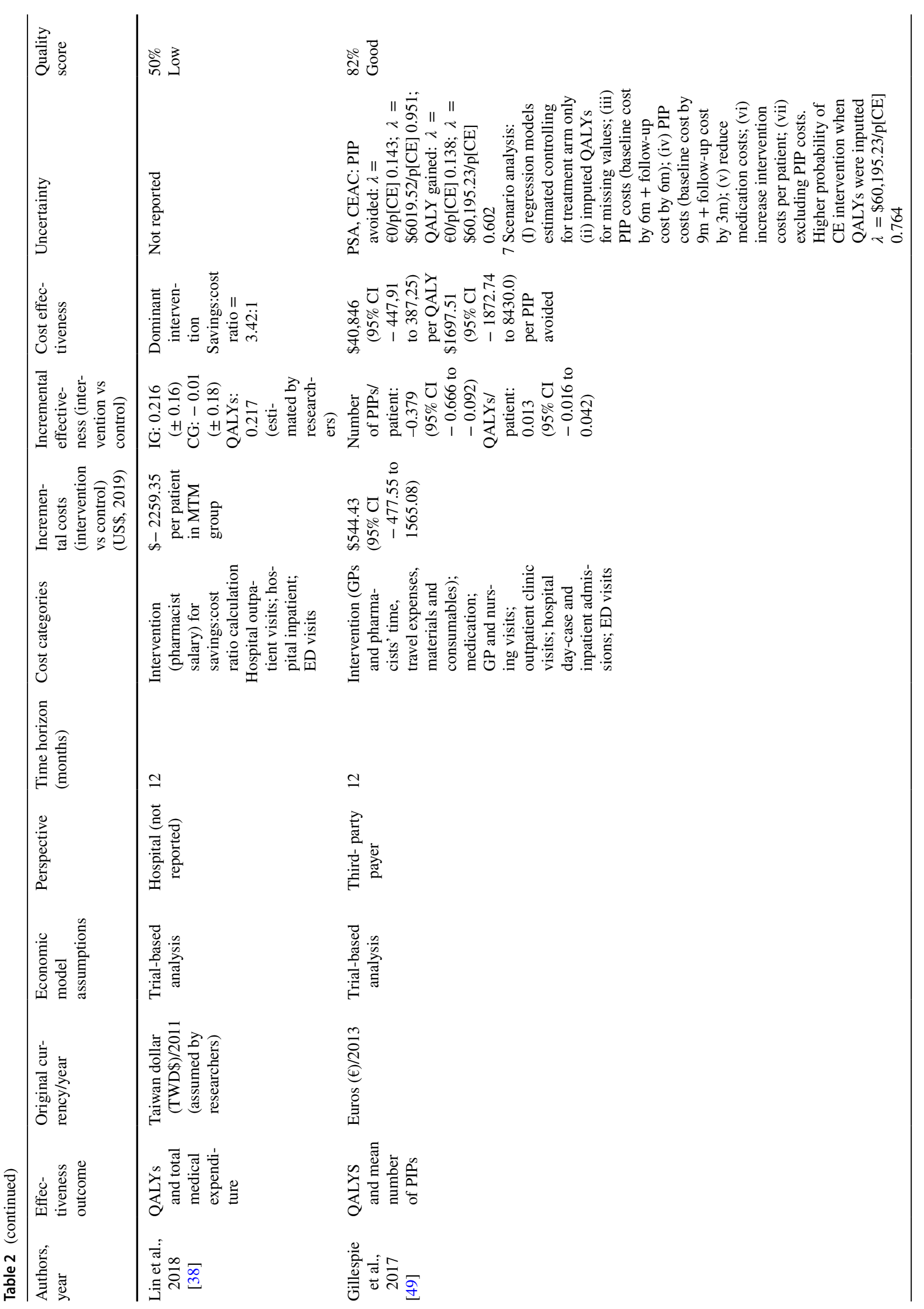




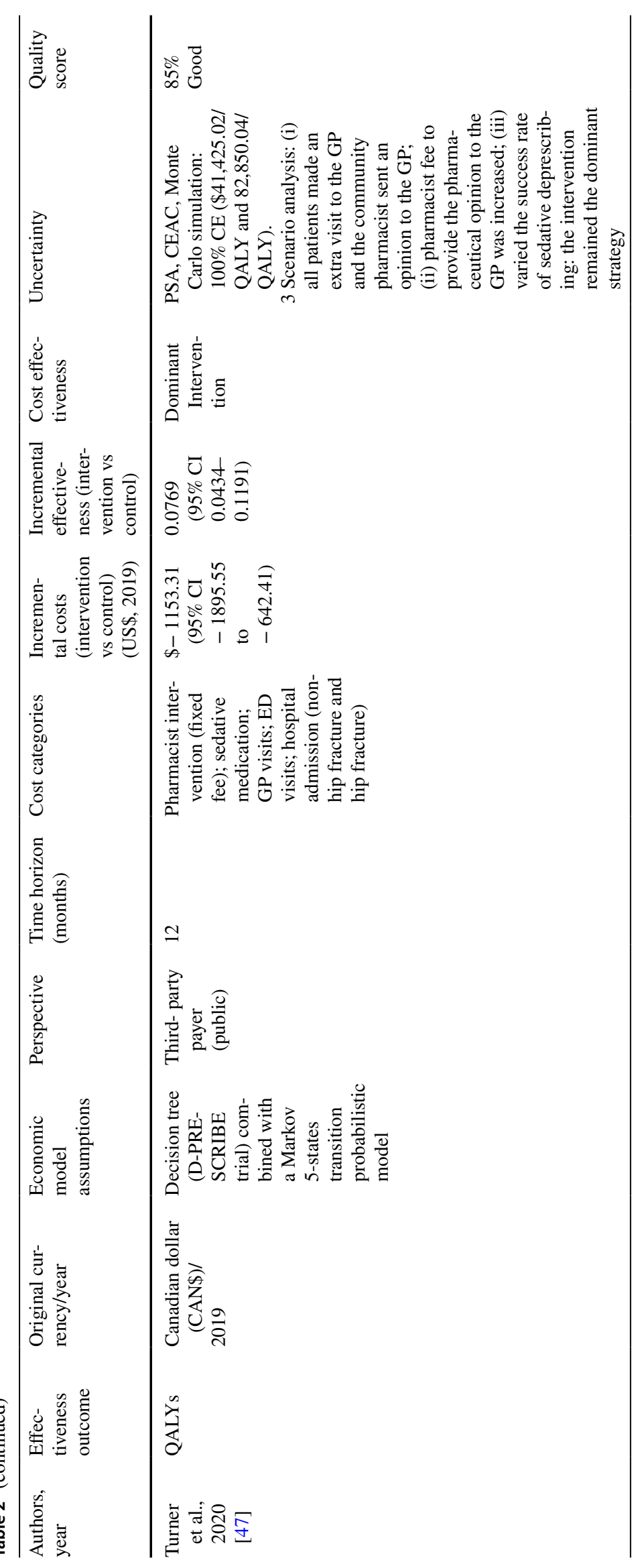




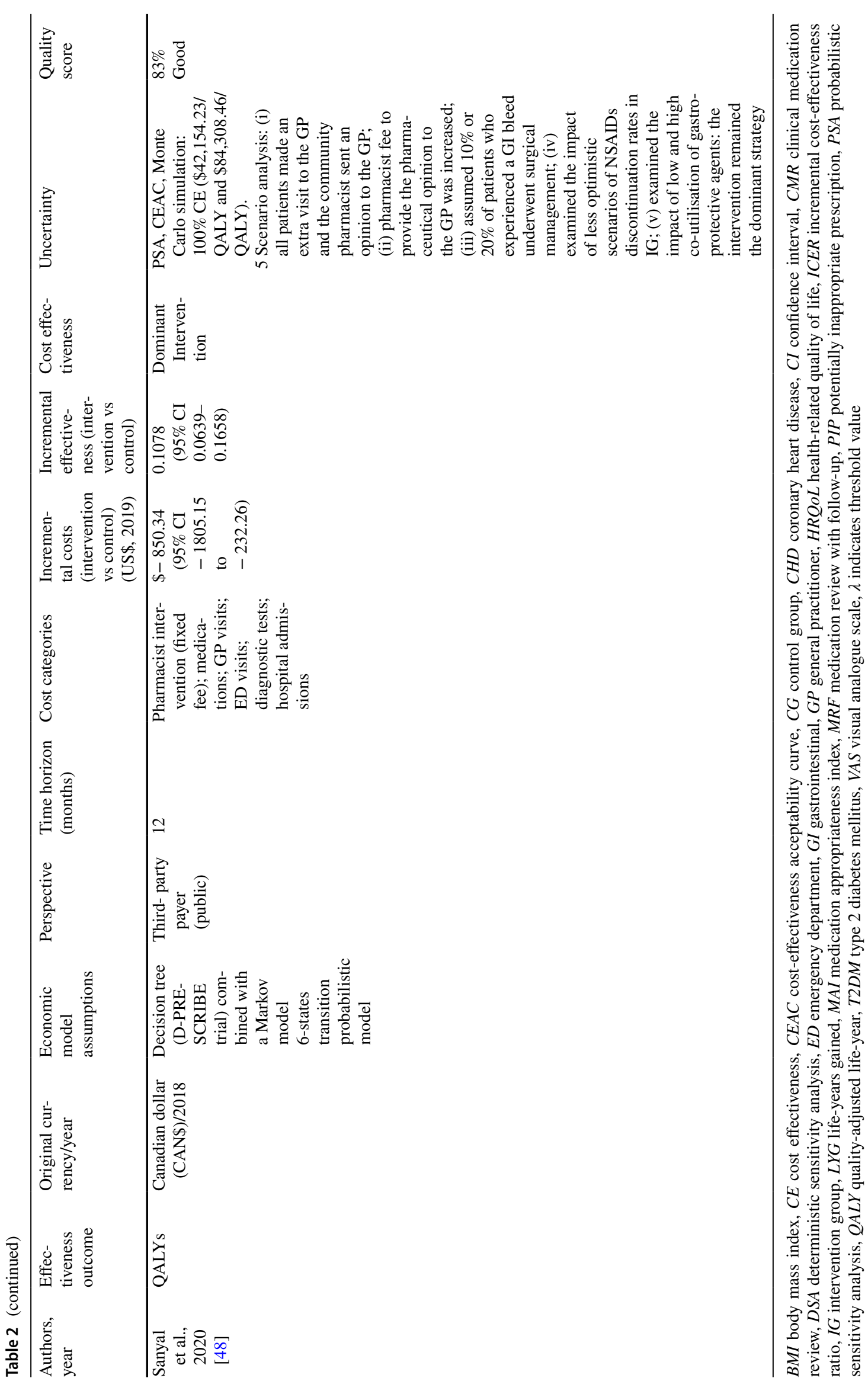


to other settings or patient groups was absent [43, 49, 51] or was poorly discussed [38, 40-42, 46] in several studies an important issue from a policy viewpoint so that decision makers can use evidence in different contexts [56]. No study scored $100 \%$ and two studies scored $\leq 50 \%$ (low) on quality assessment. In addition, the ESM presents the studies with scores of $1,0.5$ or 0 for each item of the CHEC-extended checklist.

\subsection{Main Findings}

Of the seven EE studies conducted in the community pharmacy setting [40, 41, 44-48], four studies of three interventions [45-48] found that the intervention dominated usual care by improving health outcomes and reducing costs. One intervention was a pharmacist-led medication review with a 6-month follow-up conducted in Spain (conSIGUE trial) [45, 46], and the other two were a patients' educational service focusing on patients taking sedatives [47] and non-steroidal anti-inflammatory drugs [48] conducted in Canada. Cost savings for the intervention group compared with usual care were mainly driven by a reduction in hospital admissions related to the reduction in drug-related events. Interventions remained dominant in all scenarios and/or sensitivity analyses. The remaining three EE studies of pharmacist-led medication review services for people on polypharmacy found that interventions were either cost effective with an ICER of $\$ 18,708$ per QALY [41], cost saving (\$- 236.21) [44] or not cost effective compared with usual care $(\$ 52,389$ per QALY) [40], considering the World Health Organisation's threshold.

The "RESPECT" study [41] evaluated a medication review service conducted on people aged $\geq 75$ years taking five or more medicines. Compared with the base case, a sensitivity analysis revealed that intervention was more cost effective for younger patients (aged 75-84 years) with fewer medications (five to seven medicines) and less cost effective or even dominated usual care for older patients (aged $\geq 85$ years) taking more medicines (ten or more medicines). The study that was not cost effective [40] evaluated a trial with a before-and-after study design of UK patients prescribed with four or more medicines. Pharmacists reviewed the medication for 6 months and discussed the risk of falls, pain management, adherence and general health with patients. A small but significant decrease in the number of falls, gains in quality of life and medicine adherence was observed. Overall, the mean costs per patient were higher in the 6-month follow-up compared with the pre-intervention period, mostly derived from the intervention and other (non-detailed) National Health Service costs. A further 12-month ICER estimation was made on the assumption that the 6-month gains would remain constant with no further costs, resulting in a cost-effective strategy compared with usual care $(\$ 19,179$ per QALY). The intervention found to be cost saving [44] was a clinical medication review focused on patients' preferences, delivered to older Dutch adults aged $\geq 70$ years using seven or more long-term medicines. Intervention gains were inconsistent with no benefits on HRQoL measured with the generic EQ-5D-5L instrument, and small benefits on health-related complaints, and HRQoL measured with the EQ-Visual Analogue Scale. However, the intervention compared with usual care led to cost savings, resulting in a $>90 \%$ likelihood of the intervention to be cost saving from a societal perspective. The highest savings were derived from a reduction in institutional and informal care in the intervention group at the 6-month follow-up [44].

Overall, regarding incremental effectiveness, there were no major variations between studies. Incremental QALYs varied from -0.00217 [44] to 0.108 [48]. Greater differences were found regarding incremental costs, varying between \$- 1153 [47] and \$359.19 [40]. Variations were largely derived from a reduction in hospital admissions and informal care for the intervention group compared with the control group, and from wide-ranging intervention costs. Costs of intervention ranged between \$16.6 (CAN\$20) [47, 48] and \$259.7 (€199) [44].

Regarding the six studies [38, 42, 43, 49-51] conducted in outpatient, general practices, primary care and geriatric clinics, two interventions dominated usual care [38, 42], three were cost effective [43, 49, 50], and one reported a value of $\$ 881.95$ per 1 unit of medication appropriateness index change [51], a measure of appropriateness prescription rather than a measure of outcome. Cowper et al. [51] is the oldest study included, and presented the lowest quality in methodology.

In detail, the study from Taiwan [38], assessing a pharmacist-led medication review for people on polypharmacy conducted in an outpatient academic medical centre, reported positive incremental QALYs and cost savings in the intervention group compared with the control group (intervention dominated usual care). Additionally, a savings: cost ratio of 3.42:1 for a 12-month intervention was found, when total medical expenditure savings were compared with the annual salary of the clinical pharmacist enrolled in the intervention [38]. Note that this study was assessed with low methodological quality, for example, mean costs per patient in each arm were not reported, nor were details of the resource costs. The other dominant intervention compared with usual care was a medicine review focused on the withdrawal of FRIDs [42]. The intervention was associated with a risk reduction in falls and cost savings because of medical treatments avoided. The Polinder et al. [43] study also assessed the cost effectiveness of FRID withdrawal or reduction, and found that the intervention was cost effective with an estimated cost of $\$ 1085.84$ per QALY gained. The total fall-related healthcare costs did not differ significantly between groups; however, the FRID withdrawal reduced the medication costs. Furthermore, differences 
in effectiveness were significant and positive (incremental effectiveness $=0.05$ QALYs) [43] . The intervention was delivered by a research physician supported by a research nurse who was responsible for a patient's follow-up via the phone. The two 12-month medication reviews, delivered in Chile [50] for people on polypharmacy enrolled in a cardiovascular disease prevention programme, and in Ireland for people taking specific classes of PIMs [49], were both assessed as cost effective compared with usual care, with ICERs of $\$ 434.4$ and \$40,846 per QALY, respectively. A scenario and subgroup analysis performed by Ahumada-Canale et al. [50] found that all iterations cost less than $\$ 1700$ per QALY, and that dominant iterations increased to $41.0 \%$ when considering only patients taking more than nine medicines. In the case of the Irish study, a higher probability of the intervention being cost effective was found when QALYs were inputted for missing data [49]. Overall, no major variations in incremental QALYs (0.013 [49], 0.05 [43] and 0.063 [50]) were found across studies conducted in outpatient, primary care, general practices or geriatric clinics with the exception of the Lin et al. study [38]. Regarding costs, greater differences were observed among studies driven mainly by inpatient admissions and medication and intervention total costs. This latter item ranged between $\$ 77.6(€ 58)$ [49] and \$167 (€120) [43].

The study assessing the cost effectiveness of a pharmacist-led medication review intervention at a patient's home [39] showed that this service was not cost effective (\$112,932 per QALY). The intervention was delivered to patients aged $\geq 80$ years who had an emergency visit for any cause. Patients in the intervention group had higher community, primary and hospital care costs, with a slight mean positive difference in QALYs compared with the control group (incremental QALYs $=0.0075$ ).

\section{Discussion}

This systematic review was conducted to identify and summarise available evidence of the economic value of deprescribing interventions among community-dwelling older adults. To the best of our knowledge, this is the first review gathering economic evidence of interventions that seek to reduce or withdraw medications that might be causing harm or might no longer be of benefit. Fourteen full EE studies assessing 13 interventions were identified.

Of these, nine interventions assessed in ten papers found that deprescribing interventions either dominated $(n=5)$ $[38,42,45-48]$ or were cost effective $(n=4)$ [41, 43, $49,50]$ compared with usual care, considering the World Health Organization threshold of $1 \mathrm{GDP} / \mathrm{capita}$. One other EE reported cost savings with the intervention being at least as effective as usual care [44], and another found a cost of $\$ 881.95$ per medication appropriateness index unit change in the intervention compared with usual care, concluding that the deprescribing intervention assessed can improve prescription and reduce inappropriate medications [51]. However, this conclusion can be challenged, as the cost effectiveness depends on each authority's willingness to pay for this type of outcome, and there is no standard acceptable threshold for a medication appropriateness index. Only two deprescribing interventions were found not to be cost effective compared with usual care [39, 40], the one delivered at a patient's home [39], and the other conducted at the community pharmacy [40]. Nonetheless, for the latter, a 12-month scenario found the intervention compared with usual care to be cost effective $(\$ 19,178.66$ per QALY) within the country's World Health Organization's threshold [57].

The deprescribing interventions $(n=9)$ were mostly some type of medication review conducted on overall medication [38-41, 44, 46, 49-51], and performed largely by a community or clinical pharmacist [38-41, 44-46, 50, 51] with multidisciplinary cooperation, an approach that has been described as advantageous for the success of this type of intervention [58]. The positive findings for these interventions are mostly in line with those reported in a recent systematic review of cost effectiveness of advanced pharmacy services [59]. The review concluded that advanced services, where deprescribing interventions fit, appear to be cost effective when delivered in community and primary care settings, but not in home-based settings [59]. However, it is important to note that these interventions can be complex and depend on contextual factors, such as the existence of an efficient multi-professional cooperation, available communication channels and integration of care. For some interventions, such as the one described in the conSIGUE studies [45, 46], despite the dominance of the intervention, the level of cooperation and communication between the community pharmacists and the general practitioners did not seem structured. Although these interventions were carried out with professional cooperation, the studies highlighted the fragmentation and lack of structured integration of care, as well as an excessive pharmacological approach to health problems.

The other four interventions targeted specific class(es) of medicines through a directed physician-led medication review [42, 43] and a pharmacist-led patient educational intervention $[47,48]$. Overall findings suggest that these strategies can be an efficient method to reduce costs with positive gains in health-related outcomes, especially on a large scale, as discussed previously by Bloomfield et al. [17]. Moreover, these conclusions based on experimental studies are strengthened with results presented in other studies with different study designs. For example, in a theoretical modelling study, Moriarty et al. [60] concluded that interventions to reduce the long-term use of non-steroidal 
anti-inflammatory drugs, benzodiazepines and proton-pump inhibitors are cost-effective strategies; and in a similar study based on pharmacy dispensing data, Chau et al. [61] estimated cost savings and effect gains (QALYs) for a successfully inappropriate proton-pump inhibitor withdrawal, after non-steroidal anti-inflammatory drugs and low-dose acetylsalicylic acid cessation. Overall, with the exception of one moderate-quality study [40], deprescribing interventions delivered in the community pharmacies or general practices/ outpatients clinic settings were cost saving, cost effective or dominant despite some differences in how and to whom they were delivered.

Nevertheless, these findings should be considered with some caution. Five studies were considered to have low or moderate methodological quality, failing to report and assess important aspects. Regarding the time horizon, all studies in the review adopted a short-term perspective ( $\leq 12$ months), which may be inadequate to capture all potential long-term effects of medicine withdrawal. The type of intervention includes therapy discontinuation that may affect, for example, disease progression or the occurrence of long-term side effects [29], and at the same time, the effect of the intervention may have a limited effect in time, particularly after it is ended. Thus, the cost-effectiveness findings of these studies might be overrated or underrated, considering that the health might improve or deteriorate, and related adverse events might occur or be avoided over time. However, in studies with long-term horizons, investigators must anticipate outcome progression over time for treatment and control groups, which can be difficult to do. Another issue to consider is that private payer's perspective studies generally require relatively short-term horizons (1-2 years) [62]. Still, another aspect that needs to be considered is that most EEs are based on one experimental trial, subject to major or minor biases and confounding variables related to the study design, and that does not cover all evidence in the research area. The lack of large real-world-evidence is an issue, especially when considering that complex interventions greatly depend on the context in which they are delivered (e.g. cultural characteristics, socioeconomic status, patients' literacy, patients and healthcare provider engagement).

A positive fact is that most of the studies [38-41, 43-50] reported cost-effectiveness ratios using QALYs as the effectiveness measure, assessed by the EQ-5D generic instrument, which thereby facilitates comparisons between services for decision-making assessment and resource allocation. However, across studies, a low magnitude of QALY gains was observed even if other outcomes with an expected positive impact on patients' HRQoL were significantly improved (e.g. number of PIPs per patient, reduced health-related complaints). This raises the question of whether there is a lack of sensitivity in the EQ-5D instrument for elderly patients or the intervention is not sufficiently impactful to improve the quality of life in a short period of time $[63,64]$. As incremental effectiveness was similar across studies, the variations in ICERs depended mostly on the incremental costs. Thus, an important concern is the type and valuation of resources included in each economic analysis, even the intervention costs. In most studies, the impact of varying these parameters was assessed in a scenario analysis, showing no substantial changes in conclusions drawn.

Heterogeneity between interventions, differences in population characteristics, methodology limitations, country-specific context, variety of settings, and type of healthcare system organisation and funding hinders a clear conclusion on the cost effectiveness, and on the generalisation and transferability of these findings. Nevertheless, it can be argued that there is economic evidence that supports the positive value of deprescribing interventions across countries and settings. In an era when an ageing population and multimorbidity are rising, small gains applied to a large proportion of people can become significant. However, for this to happen, it is necessary to implement country-wide measures.

Overall, it is important to point out that the studies included in this review reported ad-hoc interventions delivered in a specific context and/or region. Despite their relevance, there is a lack of wider evidence regarding these interventions. On a larger scale, the outcomes can be different from those found in a specific locality or region because PIM prevalence, level of professional cooperation, patients' characteristics, acceptance of the intervention and other factors may vary across regions. Additionally, there are no international comparisons of the same intervention that allow a conclusion to be drawn on which context is the most favorable to cost effectiveness. Moreover, a subgroup analysis should be explored and target patients who would most likely benefit from deprescribing interventions, as its effects may vary across therapeutic classes, number of medicines taken, and patients' age and lifespans, as discussed elsewhere [20, 22].

\subsection{Limitations}

There are some potential limitations to this study. First, it is restricted to peer-reviewed studies, which may have caused bias by excluding health technology assessment reports not submitted to this process, for example. Furthermore, papers from European countries not published in the English language could have been missed, as we could not access Embase, which is the most likely to cover such papers. However, seven electronic databases (generic and key databases) were searched with the goal of identifying as many relevant studies as possible. Second, the possibility of publication bias may have affected the review findings, 
as negative results are less likely to be published. Third, the appraisal of the methodological quality of the studies using the CHEC-extended checklist was susceptible to the subjective judgements of the reviewers. However, the assessment was always conducted and agreed upon by at least two reviewers, which may have reduced individual discernment. Despite these limitations, the findings of this systematic review are valuable and contribute to a more comprehensive knowledge of the economic value of deprescribing interventions for community-dwelling older adults.

\section{Conclusions}

Despite the growing interest and research on the effectiveness of deprescribing interventions, economic evidence has been studied only recently. Different outcomes were found among studies, but overall findings point to the cost effectiveness of interventions, which in some cases are even dominant. Population-based studies considering different geographies, other targeted medications and equity concerns, as well as more robust EEs regarding a long-term impact assessment, are needed to support evidence-based decisions on the implementation of interventions to deprescribe inappropriate medicines for community-dwelling older adults. Considering contextual factors and observed heterogeneity among studies, transferability assessment of relevant interventions also needs to be addressed before their adoption by other countries.

Supplementary Information The online version contains supplementary material available at https://doi.org/10.1007/s40273-021-01120-8.

\section{Declarations}

Funding No funding was used in the preparation of this article.

Conflicts of interest/competing interests All authors have completed the International Committee of Medical Journal Editors (ICMJE) disclosure form. Sónia Romano, Débora Figueira and Inês Teixeira are employees of the Portuguese National Association of Pharmacies. Julian Perelman has no conflicts of interest to declare.

Ethics approval Not applicable.

Consent to participate Not applicable.

Consent for publication Not applicable.

Availability of data and material All data are appended as supporting information.

Code availability Not applicable.
Authors' contributions SR conceived the study and performed the literature search. Data collection and analysis were performed by all authors (SR, DF, IT and JP). The first draft of the manuscript was written by SR, and all authors reviewed and edited all versions of the manuscript. All authors read and approved the final manuscript.

\section{References}

1. European Commision. The 2018 ageing report. Underlying assumptions and projection methodologies. Luxembourg. 2017. https://doi.org/10.2765/286359.

2. European Commission-Eurostat. Ageing Europe: looking at the lives of older people in the EU. Eur Union. 2019. https://doi.org/ 10.1136/bmj.315.7115.1103.

3. OECD/European Union. Health at a glance: Europe 2020: state of health in the EU Cycle. Paris: OECD Publication; 2020. https:// doi.org/10.1787/82129230-en.

4. Beard J, Officer A, de Carvalho I, Sadana R, Pot A, Michel J, et al. The World report on ageing and health: a policy framework for healthy ageing. Lancet. 2016;387:2145-54. https://doi.org/10. 1016/S0140-6736(15)00516-4.

5. Nguyen H, Manolova G, Daskalopoulou C, Vitoratou S, Prince M, Prina AM. Prevalence of multimorbidity in community settings: a systematic review and meta-analysis of observational studies. J Comorbidity. 2019;9:2235042X1987093. https://doi.org/10.1177/ $2235042 \times 19870934$.

6. Whitty CJM, MacEwen C, Goddard A, Alderson D, Marshall M, Calderwood $\mathrm{C}$, et al. Rising to the challenge of multimorbidity. BMJ. 2020;368:I6964. https://doi.org/10.1136/bmj.16964.

7. Midão L, Giardini A, Menditto E, Kardas P, Costa E. Polypharmacy prevalence among older adults based on the survey of health, ageing and retirement in Europe. Arch Gerontol Geriatr. 2018;78:213-20. https://doi.org/10.1016/j.archger.2018.06.018.

8. Hyttinen V, Jyrkkä J, Valtonen H. A systematic review of the impact of potentially inappropriate medication on health care utilization and costs among older adults. Med Care. 2016;54:950-64. https://doi.org/10.1097/MLR.0000000000000587.

9. Fu A, Jiang J, Reeves JH, Fincham J, Liu G, Perri M. Potentially inappropriate medication use and healthcare expenditures in the US community-dwelling elderly. Med Care. 2007;45:472-6. https://doi.org/10.1097/01.mlr.0000254571.05722.34.

10. Tommelein E, Mehuys E, Petrovic M, Somers A, Colin P, Boussery K. Potentially inappropriate prescribing in community-dwelling older people across Europe: a systematic literature review. Eur J Clin Pharmacol. 2015;71:1415-27. https://doi.org/ 10.1007/s00228-015-1954-4.

11. Wallace E, Mcdowell R, Bennett K, Fahey T, Smith SM, Kritchevsky S. Impact of potentially inappropriate prescribing on adverse drug events, health related quality of life and emergency hospital attendance in older people attending general practice: a prospective cohort study. J Gerontol A Biol Sci Med Sci. 2017;72:271-7. https://doi.org/10.1093/gerona/glw140.

12. Reeve E, Gnjidic D, Long J, Hilmer S. A systematic review of the emerging definition of "deprescribing" with network analysis: implications for future research and clinical practice. Br J Clin Pharmacol. 2015;80(6):1254-68. https://doi.org/10.1111/bcp. 12732 .

13. Scott IA, Hilmer SN, Reeve E, Potter K, Le CD, Rigby D, et al. Reducing inappropriate polypharmacy: the process of deprescribing. JAMA Intern Med. 2015;175:827-34. https://doi.org/10. 1001/jamainternmed.2015.0324.

14. Farrell B, Pottie K, Rojas-Fernandez CH, Bjerre LM, Thompson W, Welch V. Methodology for developing deprescribing 
guidelines: using evidence and GRADE to guide recommendations for deprescribing. PLoS ONE. 2016;11:e0161248. https:// doi.org/10.1371/journal.pone.0161248.

15. Reeve E. Deprescribing tools: a review of the types of tools available to aid deprescribing in clinical practice. J Pharm Pract Res. 2020;50:98-107. https://doi.org/10.1002/jppr.1626.

16. Iyer S, Naganathan V, McLachlan AJ, Le Couteur DG. Medication withdrawal trials in people aged 65 years and older: a systematic review. Drugs Aging. 2008;25:1021-31. https://doi.org/10.2165/ 0002512-200825120-00004.

17. Bloomfield HE, Greer N, Linsky AM, Bolduc J, Naidl T, Vardeny $\mathrm{O}$, et al. Deprescribing for community-dwelling older adults: a systematic review and meta-analysis. J Gen Intern Med. 2020;35:3323-32. https://doi.org/10.1007/s11606-020-06089-2.

18. Tecklenborg S, Byrne C, Cahir C, Brown L, Bennett K. Interventions to reduce adverse drug event-related outcomes in older adults: a systematic review and meta-analysis. Drugs Aging. 2020;37(2):91-8. https://doi.org/10.1007/s40266-019-00738-w.

19. Cooper JA, Cadogan CA, Patterson SM, Kerse N, Bradley MC, Ryan $\mathrm{C}$, et al. Interventions to improve the appropriate use of polypharmacy in older people: a Cochrane systematic review. BMJ Open. 2015;5(12):e009235. https://doi.org/10.1136/bmjop en-2015-009235.

20. Page AT, Clifford RM, Potter K, Schwartz D, Etherton-Beer $\mathrm{CD}$. The feasibility and effect of deprescribing in older adults on mortality and health: a systematic review and meta-analysis. $\mathrm{Br}$ J Clin Pharmacol. 2016;82(3):583-623. https://doi.org/10.1111/ bcp. 12975.

21. Wilsdon TD, Hendrix I, Thynne TRJ, Mangoni AA. Effectiveness of interventions to deprescribe inappropriate proton pump inhibitors in older adults. Drugs Aging. 2017;34:265-87. https://doi.org/ 10.1007/s40266-017-0442-1.

22. Pruskowski JA, Springer S, Thorpe CT, Klein-Fedyshin M, Handler SM. Does deprescribing improve quality of life? A systematic review of the literature. Drugs Aging. 2019;36:1097-110. https:// doi.org/10.1007/s40266-019-00717-1.

23. Santos NSD, Marengo LL, Moraes FDS, Barberato FS. Interventions to reduce the prescription of inappropriate medicines in older patients. Rev Saude Publica. 2019;53:7. https://doi.org/10. 11606/S1518-8787.2019053000781.

24. Hansen CR, O’Mahony D, Kearney PM, Sahm LJ, Cullinan S, Huibers CJA, et al. Identification of behaviour change techniques in deprescribing interventions: a systematic review and metaanalysis. Br J Clin Pharmacol. 2018;84:2716-28. https://doi.org/ 10.1111/bcp.13742.

25. Avery AJ, Bell BG. Rationalising medications through deprescribing. BMJ. 2019;364:I570. https://doi.org/10.1136/bmj.1570.

26. Centre for Reviews and Dissemination. CRD's guidance for undertaking reviews in health care. York: CRD University of York; 2008.

27. Page MJ, McKenzie JE, Bossuyt PM, Boutron I, Hoffmann TC, Mulrow CD, et al. The PRISMA 2020 statement: an updated guideline for reporting systematic reviews. BMJ. 2021;372: n71. https://doi.org/10.1136/bmj.n71.

28. European Commission. Ageing Europe: looking at the lives of older people in the EU. Eurostat. 2020. https://doi.org/10.2785/ 628105 .

29. Drummond M, Sculpher M, Claxton K, Stoddart G, Torrance G. Methods for the economic evaluation of health care programmes. 4th ed. New York: Oxford University Press; 2015.

30. Shemilt I, Thomas J, Morciano M. A web-based tool for adjusting costs to a specific target currency and price year. Evid Policy. 2010;6:51-9. https://doi.org/10.1332/174426410X482999.

31. Tan-Torres Edejer T, Baltussen R, Adam T, Hutubessy R, Acharya A, Evans DB, Murray CJ. Making choices in health: WHO guide to cost-effectiveness analysis. Geneva: World Health Organization; 2003.

32. The World Bank. GDP per capita, PPP (current international \$)—United States I Data. https://www.data.worldbank.org/indic ator/NY.GDP.PCAP.PP.CD?locations=US. Accessed 14 May 2021.

33. Evers S, Goossens M, de Vet H, van Tulder M, Ament A. Criteria list for assessment of methodological quality of economic evaluations: consensus on health economic criteria. Int J Technol Assess Health Care. 2005;21:240-5.

34. Odnoletkova I, Goderis G, Pil L, Nobels F, Aertgeerts B, Annemans L, et al. Cost-effectiveness of therapeutic education to prevent the development and progression of type 2 diabetes: systematic review. J Diabetes Metab. 2014;5:5-11. https://doi. org/10.4172/2155-6156.1000438.

35. CHEC list: consensus health economic criteria. Research, Maastricht University. https://www.maastrichtuniversity.nl/research/ caphri/our-research/creating-value-based-health-care/chec-listconsensus-health-economic. Accessed 20 Mar 2021.

36. van Mastrigt GAPG, Hiligsmann M, Arts JJC, Broos PH, Kleijnen J, Evers SMAA, et al. How to prepare a systematic review of economic evaluations for informing evidence-based healthcare decisions: a five-step approach (part 1/3). Expert Rev Pharmacoecon Outcomes Res. 2016;16:689-704. https://doi.org/10. 1080/14737167.2016.1246960.

37. Wijnen B, Van Mastrigt G, Redekop W, Majoie H, De Kinderen R, Evers SMAA. How to prepare a systematic review of economic evaluations for informing evidence-based healthcare decisions: data extraction, risk of bias, and transferability (part 3/3). Expert Rev Pharmacoecon Outcomes Res. 2016;16:72332. https://doi.org/10.1080/14737167.2016.1246961.

38. Lin H-W, Lin C-H, Chang C-K, Chou C-Y, Yu I-W, Lin C-C, et al. Economic outcomes of pharmacist-physician medication therapy management for polypharmacy elderly: a prospective, randomized, controlled trial. J Formos Med Assoc. 2018;117:235-43. https://doi.org/10.1016/j.jfma.2017.04.017.

39. Pacini M, Smith RD, Wilson ECF, Holland R. Home-based medication review in older people: is it cost effective? Pharmacoeconomics. 2007;25:171-80. https://doi.org/10.2165/00019 053-200725020-00008.

40. Twigg MJ, Wright D, Barton GR, Thornley T, Kerr C, Twigg M. The four or more medicines (FOMM) support service: results from an evaluation of a new community pharmacy service aimed at over-65s. Int J Pharm Pract. 2015;23:407-14. https:// doi.org/10.1111/ijpp.12196.

41. RESPECT Trial Team RT, Bojke C, Philips Z, Sculpher M, Campion P, Chrystyn H, et al. Cost-effectiveness of shared pharmaceutical care for older patients: RESPECT trial findings. Br J Gen Pract. 2010;60:e20-7. https://doi.org/10.3399/bjgp09X482 312.

42. Van Der Velde N, Meerding WJ, Looman CW, Pols HAP, Van Der Cammen TJM. Cost effectiveness of withdrawal of fall-risk-increasing drugs in geriatric outpatients. Drugs Aging. 2008;25:521-9. https://doi.org/10.2165/00002512-200825060-00005.

43. Polinder S, Boyé NDA, Mattace-Raso FUS, Van der Velde N, Hartholt KA, De Vries OJ, et al. Cost-utility of medication withdrawal in older fallers: results from the improving medication prescribing to reduce risk of FALLs (IMPROveFALL) trial. BMC Geriatr. 2016;16:1-10. https://doi.org/10.1186/s12877-016-0354-7.

44. Verdoorn S, van de Pol J, Hövels AM, Kwint HF, Blom JW, Gussekloo J, et al. Cost-utility and cost-effectiveness analysis of a clinical medication review focused on personal goals in older persons with polypharmacy compared to usual care: Economic evaluation of the DREAMeR study. Br J Clin Pharmacol. 2021;87:588-97. https:// doi.org/10.1111/bcp.14421. 
45. Malet-Larrea A, Goyenechea E, Gastelurrutia MA, Begona C, García-Cárdenas V, Cabases JM, Noain A, et al. Cost analysis and cost-benefit analysis of a medication review with follow-up service in aged polypharmacy patients. Eur J Health Econ. 2017;18:831-8. https://doi.org/10.1007/s10198-016-0853-7.

46. Jódar-Sánchez F, Malet-Larrea A, Martín JJ, García-Mochón L, López del Amo MP, Martínez-Martínez F, et al. Cost-utility analysis of a medication review with follow-up service for older adults with polypharmacy in community pharmacies in Spain: the conSIGUE Program. Pharmacoeconomics. 2015;33:599-610. https://doi.org/ 10.1007/s40273-015-0270-2.

47. Turner JP, Sanyal C, Martin P, Tannenbaum C. Economic evaluation of sedative deprescribing in older adults by community pharmacists. Newman AB, editor. J Gerontol A Biol Sci Med Sci. 2021;76:10617. https://doi.org/10.1093/gerona/glaa180.

48. Sanyal C, Turner JP, Martin P, Tannenbaum C. Cost-effectiveness of pharmacist-led deprescribing of NSAIDs in community-dwelling older adults. J Am Geriatr Soc. 2020;68:1090-7. https://doi.org/10. 1111/jgs.16388.

49. Gillespie P, Clyne B, Raymakers A, Fahey T, Hughes CM, Smith SM. Reducing potentially inappropriate prescribing for older people in primary care: cost-effectiveness of the Opti-Script intervention. Int J Technol Assess Health Care. 2017;33:494-503. https://doi.org/ $10.1017 / \mathrm{s} 0266462317000782$.

50. Ahumada-Canale A, Vargas C, Balmaceda C, Martinez-Mardones F, Plaza-Plaza JC, Benrimoj S, et al. Medication review with follow-up for cardiovascular outcomes: a trial based cost-utility analysis. J Comp Eff Res. 2021;10:229-42. https://doi.org/10.2217/ cer-2020-0171.

51. Cowper PA, Weinberger M, Hanlon JT, Landsman PB, Samsa GP, Uttech KM, et al. The cost-effectiveness of a clinical pharmacist intervention among elderly outpatients. Pharmacotherapy. 1998;18:327-32. https://doi.org/10.1002/j.1875-9114.1998.tb038 58.x.

52. Verdoorn S, Kwint H-F, Blom JW, Gussekloo J, Bouvy ML. Effects of a clinical medication review focused on personal goals, quality of life, and health problems in older persons with polypharmacy: a randomised controlled trial (DREAMeR-study). PLoS Med. 2019;16: e1002798. https://doi.org/10.1371/journal.pmed.1002798.

53. European Network for Health Technology Assessment [EUnetHTA]. Methods for health economic evaluations: A guideline based on current practices in Europe. 2015. https://www.eunethta.eu/wp-content/ uploads/2018/03/Methods_for_health_economic_evaluations.pdf. Accessed 9 Sept 2021

54. Massetti M, Aballéa S, Videau Y, Rémuzat C, Roïz J, Toumi M. A comparison of HAS and NICE guidelines for the economic evaluation of health technologies in the context of their respective national health care systems and cultural environments. J Mark Access Health Policy. 2015;3:24966. https://doi.org/10.3402/JMAHP.V3. 24966.

55. Roberts M, Russell LB, Paltiel AD, Chambers M, McEwan P, Krahn M. Conceptualizing a model: a report of the ISPOR-SMDM Modeling Good Research Practices Task Force-2. Med Decis Mak. 2012;32:678-89. https://doi.org/10.1177/0272989X12454941.

56. Sculpher M, Pang F, Manca A, Drummond M, Golder S, Urdahl $\mathrm{H}$, et al. Generalisability in economic evaluation studies in healthcare: a review and case studies. Health Technol Assess (Rockv). 2004;8:1-192. https://doi.org/10.3310/HTA8490.

57. Twigg MJ, Wright D, Kirkdale CL, Desborough JA, Thornley T, Barry P. The UK Pharmacy Care Plan service: description, recruitment and initial views on a new community pharmacy intervention. PLoS ONE. 2017;12: e0174500. https://doi.org/10.1371/journal. pone. 0174500 .

58. Rankin A, Cadogan CA, Patterson SM, Kerse N, Cardwell CR, Bradley MC, et al. Interventions to improve the appropriate use of polypharmacy for older people. Cochrane Database Syst Rev.
2018;9:CD008165. https://doi.org/10.1002/14651858.CD008165. pub4.

59. Dawoud DM, Haines A, Wonderling D, Ashe J, Hill J, Varia M, et al. Cost effectiveness of advanced pharmacy services provided in the community and primary care settings: a systematic review. Pharmacoeconomics. 2019;37(10):1241-60. https://doi.org/10. 1007/s40273-019-00814-4.

60. Moriarty F, Cahir C, Bennett K, Fahey T. Economic impact of potentially inappropriate prescribing and related adverse events in older people: a cost-utility analysis using Markov models. BMJ Open. 2019;9:1-9. https://doi.org/10.1136/bmjopen-2018-021832.

61. Chau SH, Sluiter RL, Hugtenburg JG, Wensing M, Kievit W, Teichert M. Cost-utility and budget impact analysis for stopping the inappropriate use of proton pump inhibitors after cessation of NSAID or low-dose acetylsalicylic acid treatment. Drugs Aging. 2020;37:67-74. https://doi.org/10.1007/s40266-019-00713-5.

62. Basu A, Maciejewski M. Choosing a time horizon in cost and costeffectiveness analyses. JAMA. 2019;321:1096-7. https://doi.org/10. 1001/JAMA.2019.1153.

63. Efthymiadou O, Mossman J, Kanavos P. Health related quality of life aspects not captured by EQ-5D-5L: results from an international survey of patients. Health Policy. 2019;123:159-65. https://doi.org/ 10.1016/J.HEALTHPOL.2018.12.003.

64. Payakachat N, Ali MM, Tilford JM. Can the EQ-5D detect meaningful change? A systematic review. Pharmacoeconomics. 2015;33:1137-54. https://doi.org/10.1007/s40273-015-0295-6.

65. Boyé NDA, van der Velde N, de Vries OJ, van Lieshout EMM, Hartholt KA, Mattace-Raso FUS, et al. Effectiveness of medication withdrawal in older fallers: results from the improving medication prescribing to reduce risk of falls (IMPROveFALL) trial. Age Ageing. 2017;46:142-6. https://doi.org/10.1093/ageing/afw161.

66. Holland R, Lenaghan E, Harvey I, Smith R, Shepstone L, Lipp A, et al. Does home based medication review keep older people out of hospital? The HOMER randomised controlled trial. BMJ. 2005;340:293. https://doi.org/10.1136/bmj.38338.674583.AE.

67. Richmond S, Morton V, Cross B, Wong ICK, Russell I, Philips Z, et al. Effectiveness of shared pharmaceutical care for older patients: RESPECT trial findings. Br J Gen Pract. 2010;60:e10-9. https://doi. org/10.3399/bjgp09X473295.

68. Hanlon JT, Weinberger M, Samsa GP, Schmader KE, Uttech KM, Lewis IK, et al. A randomized, controlled trial of a clinical pharmacist intervention to improve inappropriate prescribing in elderly outpatients with polypharmacy. Am J Med. 1996;100:428-37. https:// doi.org/10.1016/S0002-9343(97)89519-8.

69. Clyne B, Smith SM, Hughes CM, Boland F, Bradley M, Cooper JA, et al. Effectiveness of a multifaceted intervention for potentially inappropriate prescribing in older patients in primary care: a clusterrandomized controlled trial (OPTI-SCRIPT Study). Ann Fam Med. 2015;13:545-53. https://doi.org/10.1370/afm.1838.

70. Martin P, Tamblyn R, Benedetti A, Ahmed S, Tannenbaum C. Effect of a pharmacist-led educational intervention on inappropriate medication prescriptions in older adults: the D-PRESCRIBE randomized clinical trial. JAMA. 2018;320:1889-98. https://doi.org/10.1001/ jama.2018.16131. 